\title{
Implications of Apparent Pseudo-Second-Order Adsorption Kinetics onto Cellulosic Materials: A Review
}

\begin{abstract}
Martin A. Hubbe, ${ }^{a}$ Saeid Azizian, ${ }^{b}$ and Sigrid Douven ${ }^{c}$
The pseudo-second-order (PSO) kinetic model has become among the most popular ways to fit rate data for adsorption of metal ions, dyes, and other compounds from aqueous solution onto cellulose-based materials. This review first considers published evidence regarding the validity of the mechanistic assumptions underlying application of the PSO model to adsorption kinetics. A literal interpretation of the model requires an assumption that different adsorption sites on a solid substrate randomly collide with each other during a rate-limiting mechanistic step. Because of problems revealed by the literature regarding the usual assumptions associated with the PSO model, this review also considers how else to account for good fits of adsorption data to the PSO model. Studies have shown that adsorption behavior that fits the PSO model well often can be explained by diffusion-based mechanisms. Hypothetical data generated using the assumption of pseudo-first-order rate behavior has been shown to fit the PSO model very well. In light of published evidence, adsorption kinetics of cellulosic materials is expected to mainly depend on diffusionlimited processes, as affected by heterogeneous distributions of pore sizes and continual partitioning of solute species between a dissolved state and a fixed state of adsorption.
\end{abstract}

Keywords: Kinetics of adsorption; Cellulose; Wood-based materials; Mesoporous substrates

Contact information: a: North Carolina State University, Department of Forest Biomaterials, Box 8005, Raleigh, NC 27695-8005 USA; Email: hubbe@ncsu.edu; b: Bu Ali Sina University, Faculty of Chemistry, Department of Physical Chemistry, Hamedan, Iran; c: Université de Liège; Department of Chemical Engineering, B6a, Quartier Agora, Allée du six Août 13, 4000 Liège, Belgium;

* Corresponding author: hubbe@ncsu.edu

\section{Contents}

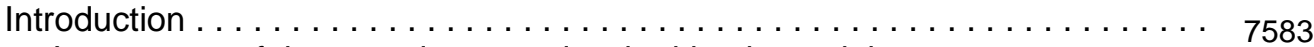

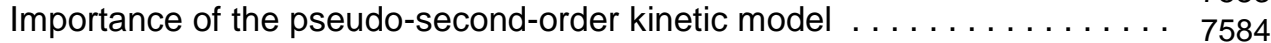

Substance of the pseudo-second-order model . . . . . . . . . . . . 7584

Suspicious aspects of the pseudo-second-order model $\ldots \ldots \ldots \ldots \ldots \ldots 7586$

Expectation that the final step of adsorption ought to be fast $\ldots \ldots \ldots \ldots 7587$

Impossibility of mass action rule in the case of a solid $\ldots \ldots \ldots \ldots \ldots 7588$

Inconsistency of the "pseudo" assumption and experimental procedure . . . 7590

Problems with energy of activation concept $\ldots \ldots \ldots \ldots \ldots \ldots \ldots \ldots 7590$

Good fits to both diffusion and the pseudo-second-order models . . . . . . 7594

Other ways to account for good fits to the pseudo-second-order model . . . . . 7595

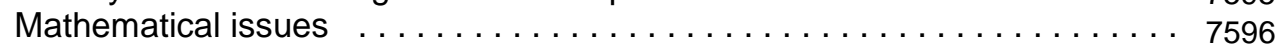

Diffusion-limited models . . . . . . . . . . . . . . . . . . . . 7597

What fits to pseudo-second-order say about cellulosic materials $\ldots \ldots \ldots \ldots 7606$

Deceleration of adsorption rate and what it means $\ldots \ldots \ldots \ldots \ldots \ldots 7606$

Potential for analysis based on fuller diffusion-based model $\ldots \ldots \ldots \ldots 7610$

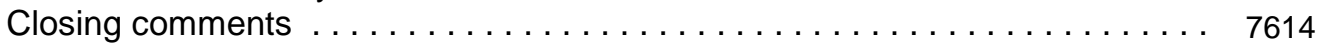




\section{INTRODUCTION}

\section{Importance of Adsorption}

Adsorbent materials, including activated carbons, zeolites, and cellulose-based materials, hold great promise as means to remove various dissolved compounds or metal ions from aqueous solution. Researchers have pursued the development of lower-cost sorbent materials and evaluated them for removal of a wide variety of pollutants. At the same time, there has been much attention to both the rates and the capacities of adsorption. Table 1 lists some review articles that cover various aspects of this topic.

Table 1. Reviews of Research Using Adsorbents to Remove Pollutants from Aqueous Systems

\begin{tabular}{|l|l|l|}
\hline Substances to be removed & Classes of adsorbents & Reference \\
\hline Metal ions & Agro-based biomass & Demirbas 2008 \\
\hline Metal ions & Cellulose-based & Hubbe et al. 2011 \\
\hline Dyes & Agro-based biomass & Salleh et al. 2011 \\
\hline Dyes & Cellulose-based & Hubbe et al. 2012a \\
\hline Dissolved petrochemicals & Cellulose-based & Hubbe et al. 2014 \\
\hline Dyes & Various adsorbents & Yagub et al. 2014 \\
\hline
\end{tabular}

Quantification of adsorption rate information generally requires the use of suitable model equations. Here the word "model" is often assumed to mean that the equations employed represent theoretically justifiable mechanisms that can - at least as an approximation - account for the observed adsorption data in a theoretical sense. Whether or not the equations are grounded in a meaningful theory, a mathematical fit of such data also could be employed when estimating the dimensions or process conditions in a planned wastewater treatment facility.

The rates of uptake of target compounds onto the adsorbent are of great importance with regards to potential scale-up and implementation of prospective systems to remove pollutants from water. If the time required for effective adsorption can be shortened, then it may be possible to decrease the retention time in a batch system or packed bed system. The size of the needed equipment might be less. Packed bed systems are often regarded as being more practical, since they avoid the need to collect suspended particles again by filtration, settling, or other means after their usage (Schweich and Sardin 1981; Ali 2014). Within a packed bed or column, each packet of fluid does not have time to fully equilibrate with adjacent particles of adsorbent as it passes through the system. Accordingly, there is an understood preference of adsorbent systems that can act fast (Sen Gupta and Bhattacharyya 2011; Largitte and Pasquier 2016).

The kinetics of adsorption also can be important for industrial processes in which compounds are being applied to solids materials from solution. Textile manufactures require a high efficiency and rate of uptake of dyes onto the fibers (Ujhelyiova et al. 2007; Varadarajan and Venkatachalam 2016). In papermaking, dyes and various other additives need to be retained in nearly quantitative manner to the surface of cellulosic fibers (Hubbe et al. 2008). In agricultural systems there is a need, in many cases, to retain nutrients or pesticides efficiently within soil after their application as solutions (Bailey and White 1964; Calvet et al. 1980a,b). Even in the case of conventional wastewater treatment, the rates of adsorption of compounds of pollutant onto sludge particles or other sorbents can impact the quality of the discharged treated water (Gupta and Suhas 2009; Inyang et al. 2016). 


\section{Importance of the Pseudo-Second-Order Kinetic Model}

The focus of this article is on one of the most popular approaches to quantitative description of the rates of uptake of substances onto sorbent materials. Based on a search of the Web of Science, one of the foundational articles describing the usage of a pseudosecond-order (PSO) model to quantify adsorption kinetics (Ho and McKay 1999) has been cited about 8000 times. It was reported in 2015 that out of 5000 citations of this work, 4500 of them indicated best fits to the PSO model, compared to alternative models or equations (Douven et al. 2015). A more recent theoretical derivation has been cited over 1000 times (Azizian 2004). The statistical agreement between adsorption data and the PSO model has been found to be high in a wide variety of situations (Sobkowski and Czerwiński 1974; Ritchie 1977; Ho and McKay 1999; Liu and Liu 2008; Hubbe et al. 2012a; Hubbe 2013; Tan and Hameed 2017).

Physicochemical soundness, reasonableness, and practical usefulness are themes that will be considered in this review article. Theoretical issues related to the PSO approach have been addressed, in particular, by the articles listed in Table 2 .

Table 2. Articles Addressing Theoretical Issues Related to the Pseudo-SecondOrder Analysis of Adsorption Rates

\begin{tabular}{|l|l|}
\hline Issues addressed & Selected references \\
\hline Initial bulk concentration too low & Azizian 2004; Lin et al. 2018 \\
\hline Activation energy requirement for surface reaction steps & Mills et al. 1995 \\
\hline Non-independence of surface sites for the rate-limiting step & Hubbe et al. 2012a \\
\hline Mistakes in copying and citation of the PSO equation & Ho 2014 \\
\hline Range of validity; fundamental basis & Douven et al. 2015 \\
\hline Usage of PSO equations merely for data fitting & Tan and Hameed 2017 \\
\hline Simultaneous fits to contradictory kinetic models & Plazinski et al. 2009 \\
\hline
\end{tabular}

Another issue, when using models to fit data from practical experiments, is the necessity to make simplifying assumptions. It has been said that all theoretical models are incorrect, but some of them are useful (Box 1976). Often it is only by making simplifying assumptions that one can begin to understand our complex world. However, there is a danger when a simplified description is being used outside of its range of validity.

A third aspect that will be considered is the potential usefulness of data fitting as a means to estimate the size and throughput of industrial equipment. Various publications have suggested that such engineering estimates can be useful for the design and optimization of facility designs for treatment of contaminated waters (Weber and Morris 1963; Wu et al. 2009a; Tseng et al. 2010; Chatterjee and Schiewer 2014; Hill 2014; Douven et al. 2015; Tan and Hameed 2017). As will be discussed, the PSO model can be used to accurately represent relationships between time and uptake of solutes from solution in a majority of typical cases.

\section{The Substance of the Pseudo-Second-Order Model}

The prefix "pseudo", when applied to chemical kinetics, refers to systems in which one of the influencing factors is held sufficiently constant during an interaction so that it does not need to be included in a mathematical description of the data (Conners 1990; Hill 2014). For instance, in the case of the pseudo-second-order (PSO) relationship, one is making the implicit assumption that any changes in the initial bulk concentration during the experiment are small enough that they do not affect the kinetic relationship (Blanchard 
et al. 1984; Liu and Liu 2008). From another perspective, the word "pseudo" can be taken to imply that a rate law for adsorption is being expressed in terms of an adsorbed amount $q$ (i.e. occupied sites of adsorption) rather than in terms of concentration $c$ of the adsorbing species.

The earliest articles to publish mathematical expressions equivalent to the PSO model of adsorption were apparently those of Sobkowski and Czerwiński (1974), Ritchie (1977), Blanchard et al. (1984), and Ho and McKay (1998a,b,c). A related mathematical relationship can be obtained also from earlier work of Coleman et al. (1956), who proposed equilibrium expressions for the formation of complexes between divalent copper and pairs of adsorption sites at the surface of peat.

\section{Differential equation for PSO and its meaning}

The differential equation proposed by Blanchard et al. (1984) can be written in generalized form as (Tan and Hameed 2017):

$$
\frac{d q}{d t}=k_{2}\left(q_{e}-q\right)^{2}
$$

In this expression, the term $q$ refers to the amount of adsorbate bound to the substrate at time $t, q_{e}$ stands for its equilibrium value, and $k_{2}$ is the pseudo-second-order rate constant.

\section{Implication concerning rate-limiting step}

Based on the structure of Eq. 1, one can draw some conclusions about the steps in the rate-limiting step of a process. The squared term in this equation is an expression of the available sites of adsorption at time $t$. Because the term is squared, one is in effect assuming that during the rate-limiting step there is a collision between two independent unoccupied sites on the adsorbent material. Thus, according to Coleman et al. (1956),

$$
2 \mathrm{P}^{-}+\mathrm{Cu}^{2+} \rightleftharpoons \mathrm{CuP}_{2}
$$

where in the cited work $\mathrm{P}^{-}$is an anionic site on the adsorbent (peat), and the copper metal ions are divalent. Coleman et al. (1956) used this expression only as a means of defining an equilibrium relationship. Blanchard et al. (1984) used the same equation as the starting point for deriving Eq. 1, which is the differential form of the PSO relationship.

\section{Integrated forms of the relationship}

The integration of Eq. 1 was initially carried out by Blanchard et al. (1984), giving the form (with the symbols used by Tan and Hameed 2017),

$$
\frac{1}{q_{e}-q}-\alpha=k_{2} t
$$

where $\alpha$ is an intercept in a presumed linear relationship. In practice, researchers can plot the experimental values of the term $\left[1 /\left(q_{e}-q\right)\right]$ against time $(t)$, from which the slope of a line found by linear regression gives the value of $k_{2}$.

In addition to Eq. 3, there are other ways to write the integrated form of the relationship (Ho 2006b). These are given (together with the other related expressions) in Table $\mathrm{A}$ in the appendix to this article (see Eqs. 3A, 3B, and 3C). In addition, some incorrect forms also have appeared in the literature, as reported by Ho (2016), which presumably resulted from mistakes in copying. 


\section{General prediction of a declining rate}

Regardless of theoretical considerations, the structure of the PSO relationship, as expressed by Eq. 1, leads to the prediction of a declining rate of uptake. That is because each increment of adsorption causes a corresponding decrease in the difference $\left(q_{e}-q\right)$. Because the term $\left(q_{e}-q\right)$ is squared, the deceleration of the adsorption rate is amplified. It follows that the PSO relationship, irrespective of any initial meaning, might be used to fit data in which some sites of adsorption take a lot longer to be filled. This is typically the case for diffusion-limited processes whereby adsorption sites far from a pellet's outer surface are more difficult to reach. Another case of strong deceleration of adsorption rate corresponds to a situation where the total number of molecules in the solution matches exactly the surface area of the adsorbent, as discussed by Douven et al. (2015). In such situations, adsorption is accompanied by strong depletion of the concentration in the bulk solution.

\section{A related kinetic model: pseudo-first-order}

Though the main focus of this review article will be on adsorption data that appear to fit better to a pseudo-second-order (PSO) kinetic model, there will be a need to refer multiple times to a related, and apparently well established kinetic relationship, the pseudofirst-order model. This model has been attributed to Lagergren (1898), and its differential form can be expressed as,

$$
\frac{d q}{d t}=k_{1}\left(q_{e}-q\right)
$$

where the definitions of $q_{e}$ and $q$ are the same as given earlier following Eq. 1. This relationship follows from an assumption that the rate-limiting step in adsorption depends on collisions between solute molecules or ions with unoccupied single sites at the surface of the adsorbent material. Integration of Eq. 4 yields (Ho and McKay 1998a,b,c; Azizian 2004):

$$
\ln \left(q_{e}-q_{t}\right)=\ln q_{e}-k_{1} t
$$

As in the case of the integrated form of the PSO relationship (Eq. 3), it is common practice, based on Eq. 5, to prepare plots of $\ln \left(q_{e}-q_{t}\right) v s$. $t$ as a means to determine the values of $k_{1}$.

\section{SUSPICIOUS ASPECTS OF THE PSO MODEL}

The purpose of this section is to discuss certain aspects of the PSO kinetic model that have caused some researchers to call into question its validity or range of applications. For example, Plazinski et al. (2009) concluded that the PSO does not correspond to any specific physical situation, but that rather it happens to be able to fit typical adsorption data as an approximation. One of the aspects raising doubt among researchers is an expectation that any "surface reaction" involved in the adsorption would likely take place quickly relative to the time needed for diffusion-dependent processes to be achieved. Another is the expected inability of pairs of unoccupied individual sites on a solid substrate to act as independent entities in any rate-limiting interaction. A third concern relates to the fact that, in almost every study of adsorption from solution, the initial concentration changes significantly, and the expression does not contain a term to account for changes in the bulk concentration. A further concern is related to the unreasonableness of having to assume a 
significant activation energy associated with typical adsorption steps of ions and other compounds onto typical substrates, especially but not restricted to cases where the participants in the surface interaction have opposite charges. Finally, some reported studies appear to have inconsistencies in the fitting of data to various models.

\section{Expectation that Final Step Ought to Be "Fast"}

Figure 1 presents a pictorial impression in which a typical cellulose-based adsorbent material in water is envisioned as a three-dimensional structure with an extensive network of pores having a wide range of diameters and lengths, some portions of which are located relatively deep within the material. Such a view, as in an earlier drawing by Tan and Hameed (2017), would suggest that the time required for diffusion ought to be a sufficient factor to account for kinetic effects. Thus, Tan and Hameed (2017) expressed an expectation that the final act of interaction of the adsorbing species with a surface site would likely take place sufficiently rapidly that it would not serve as a rate-limiting step in the overall interaction. It is commonly understood in the field of chemical kinetics that a reactive step that is relatively rapid is unlikely to be the rate-determining factor in an overall reaction rate (Connors 1990; Denisov et al. 2003; Henriksen and Hansen 2008; Rudzinski and Plazinski 2006, 2008; Soustelle 2011; Chatterjee and Schiewer 2014; Douven et al. 2015; Ancheyta Juárez 2017; Vallance 2017). Based on these considerations, it seems unreasonable to attribute limitations in overall rates of adsorption to the slowness of collisions of adsorption species with surface sites.

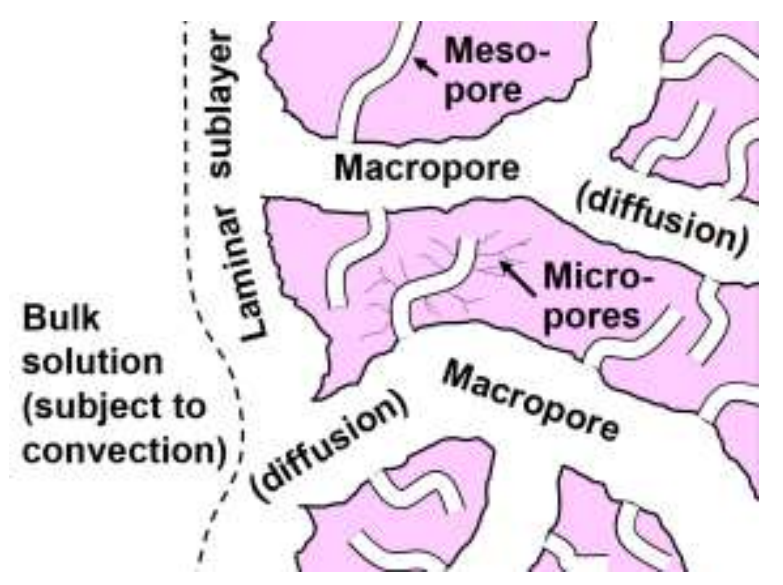

Fig. 1. Representation of a cellulosic material having a three-dimensional porous structure with a range of pore sizes. By IUPAC definition, macropores have diameter greater than $50 \mathrm{~nm}$, mesopores are in the range 2 to $50 \mathrm{~nm}$, and micropores are below $2 \mathrm{~nm}$.

Two factors that also suggest a rapid step in the ultimate attachment of a typical adsorbing species onto cellulose-based materials during a typical adsorption experiment are proximity and molecular simplicity. The word proximity can be understood by envisioning a position in Fig. 1, possibly deep within the cellulosic material within a small pore. The surface area associated with the smallest pores is likely to represent a large proportion of the available adsorption sites, especially in the case of adsorbents such as activated carbons (Perlach 1981; Do and Do 2003; Yahya et al. 2015; Suhas et al. 2016) and swollen kraft pulp fibers (Stone and Scallan 1968; Alince and van de Ven 1997; Berthold and Salmén 1997; Alince 2002). Within a small pore the adsorbing species are constrained to be very close to a surface. A majority of the studies that have shown good 
fits to the PSO model have involved relatively small and simple adsorbate species. Since small molecules and ions tend to diffuse rapidly in solution, they would be able to adopt essentially all of their possible molecular conformations within tiny pore spaces in fractions of seconds, including high numbers of collisions with, and possible detachments from, an adjacent solid surface. Relatively long times for a molecule to collide with and adsorb onto a surface, excluding times required for diffusion, have been documented only for quite large molecules, such as high-mass polyelectrolytes (Ödberg et al. 1993; Alince 2002; Wu et al. 2009b).

Another concern that has been expressed about rate expressions that are based on surface reactions (such as the PSO), is that they do not place needed emphasis on effects related to diffusion (Hubbe et al. 2012a; Kumar et al. 2017). Mechanisms based on surface reactions as the slow step in adsorption have no way to account for the time needed for diffusion to take place. This concern would be expected to be important in the case of cellulosic materials, given their known complexity of three-dimensional pore structure. If the overall process can be described as shown in Fig. 1, then any model based only on surface reactions could be expected to miss many important factors that influence rates of adsorption. Haerifar and Azizian (2013) presented a new kinetic model that accounts for systems in which both surface reaction and diffusion affect the rate of adsorption at a solid/solution interface.

\section{Impossibility of Mass Action Rule in Case of a Solid}

The concept of mass-action, which is a fundamental principle of chemical kinetics, views chemical reactions in terms of collisions among the participating species (Denisov et al. 2003; Pekar 2005; Doktorov and Kipriyanov 2007; House 2007; Rudzinski and Plazinski 2008). For example, Boyd et al. (1947) mentioned the mass action principles as justification for use of a pseudo-first-order kinetic model. The order of a reaction, as expressed in a rate equation, should be consistent with the numbers of species that need to simultaneously collide during the rate-limiting step (Connors 1990; Denisov et al. 2003; Liu and Liu 2008). To take a very simple example, suppose that compound A is reacting with $\mathrm{B}$ to form $\mathrm{AB}$, as in

$$
\mathrm{A}+\mathrm{B} \rightarrow \mathrm{AB}
$$

If one has determined that in fact Eq. 6 represents the rate-limiting step, at a fundamental level, then a rate expression can be written in the form,

$$
\mathrm{d}[\mathrm{AB}] / \mathrm{d} t=k[\mathrm{~A}][\mathrm{B}]
$$

where the terms $[\mathrm{A}]$ and $[\mathrm{B}]$ are concentrations. Based on Eq. 7 it can be said that the reaction is first-order with respect to both $\mathrm{A}$ and $\mathrm{B}$. If, somehow, the concentration of $\mathrm{A}$ were held constant during the process, then it would be possible to write an equivalent expression,

$$
\mathrm{d}[\mathrm{AB}] / \mathrm{d} t=k^{\prime}[\mathrm{B}]
$$

in which the modified rate constant $k^{\prime}$ incorporates the concentration of $\mathrm{A}$, which is treated as a constant. Equation 8 can be called a form of "pseudo-first-order" rate expression, since under the conditions of testing, the rate depends only on [B].

Next, one can consider the forward step of a dimerization reaction, as in Eq. 9. In this case, assuming that Eq. 9 represents a rate-limiting step at a fundamental level, the 
reaction order is two with respect to species A. In other words, the reaction is second-order with respect to [A].

$$
\begin{aligned}
& \mathrm{A}+\mathrm{A} \rightarrow \mathrm{A}_{2} \\
& \mathrm{~d}\left[\mathrm{~A}_{2}\right] / \mathrm{d} t=k[\mathrm{~A}]^{2}
\end{aligned}
$$

With these examples in mind, the pseudo-second-order relationship, as expressed in Eq. 1 (repeated below) implies some type of collision or interaction between pairs of independent sites of adsorption during the rate-limiting step.

$$
\frac{d q}{d t}=k_{2}\left(q_{e}-q\right)^{2}
$$

The problem with the concept just described is that it requires the solid substrate to behave, in terms of the interactions responsible for adsorption, as if it were a liquid. That's essentially what it would mean for pairs of the available sites, represented by the term $\left(q_{e}\right.$ $-q$ ) in Eq. 1 to be capable if independent action in a proposed second-order rate-limiting process. The situation is illustrated in Fig. 2. Here, in order to model a PSO mechanism with respect to unoccupied surface sites, we assume that an individual adsorbing species in the solution has three possible interactions with an adjacent surface:

(a) It collides with an occupied site (result: no sticking).

(b) It collides with a single unoccupied site (result: no sticking).

(c) It collides with two unoccupied sites at once (result: sticking).

In order to justify a second-order relationship, one has to assume that the sites on the surface are independent of each other. Also one needs to assume that the presence of two unoccupied sites side-by-side is a consequence of random change. Thus, Fig. 2 depicts the unoccupied sites as moving around randomly, i.e. surface diffusion of the alreadyadsorbed species. The topic of surface diffusion will be considered in more depth later in this article. Though the situation represented in Fig. 2 is physically possible, it is suggested here that it does not offer a credible justification for the use of the PSO model to fit typical data for adsorption from solutions.

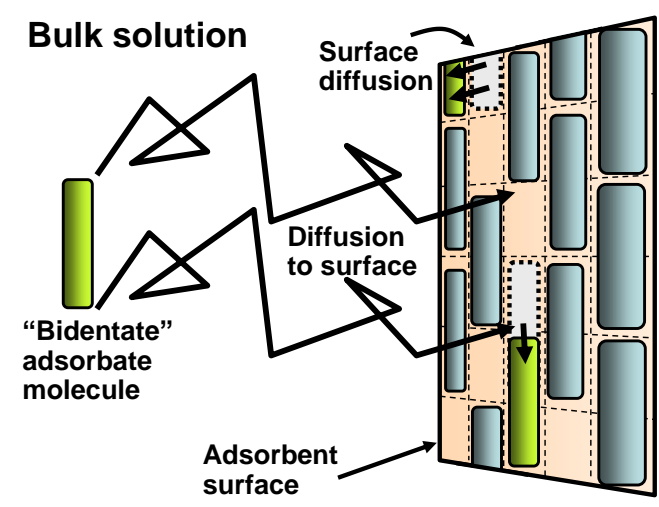

Fig. 2. Schematic illustration to justify use of a PSO mechanism, visualizing unoccupied sites of adsorption moving randomly on the surface and colliding with a frequency proportional to the square of such sites 
As an alternative to the surface-adsorption mechanism, one could speculate that some of the available surface sites on an adsorbent material such as peat might be located on separate filaments of cellulosic matter, and that the mutual diffusion of such filaments could possible give rise to collisions between two of the surface sites. Such a concept could be used to rationalize the usage of Eqs. 1 and 3. But realistically, the binding of most materials is expected to involve either individual sites, which might in some cases be composed of two or more functional groups at the surface of an adsorbent. Adjacent functional groups or available locations at a solid surface, being attached to the surface, would not be able to independently collide in a manner that would give rise to the relationship expressed in Eqs. 1 and 3. This problem, when applying Eqs. 1 and 3 to typical adsorption phenomena on solid substrates, was already noted in some earlier publications (Hubbe et al. 2012a; Hubbe 2013; Hubbe et al. 2014). In particular, a pair of adsorption sites each bound to a solid substrate would act as a single site of adsorption during a realistic rate-limiting step in the process (Hubbe et al. 2014). For this reason, the fact that adsorption kinetics often can be well fitted to PSO kinetics may need to be explained starting with different assumptions.

\section{Inconsistency of "Pseudo" Assumption and Experimental Procedures}

If one insists upon a strictly accurate analysis, then there is a logical inconsistency inherent in the way that the PSO model is handled in almost every published study where it is used to fit adsorption data. Blanchard et al. (1984) introduced the working assumption that the value of bulk concentration would remain sufficiently constant during an experiment such as to allow useful analysis. The term "pseudo" implies that the bulk concentration of adsorbate remains constant during the experiment. However, the results of most adsorption studies are determined based on measured changes in the bulk concentration (Azizian 2004; Hubbe et al. 2012a). Thus, the very quantity that is assumed to remain constant is required to change in order to be able to complete the analysis.

Evidence that the problem just described may be important relative to the interpretation of adsorption data comes from studies in which the fitted results were different depending on the initial concentration of adsorbate. A relatively low initial concentration makes it more likely that the overall change in bulk concentration during an adsorption experiment is sufficient to invalidate the working assumption that the concentration remains essentially the same, for purposes of estimation. Strong dependencies of PSO fitting parameters on the initial concentration have been reported in several studies (Ho and McKay 1998a; Azizian 2004; Crini et al. 2007; Hameed et al. 2007; Tan et al. 2008; Lin et al. 2018). In the (mostly theoretical) case where diffusion is not a factor limiting the rate of adsorption, Azizian (2004) found that relatively high values of the initial concentration of an adsorbate tend to give good fits to a pseudo-first-order rate behavior, whereas relatively low concentrations often give better fits to a PSO model.

\section{Problems with the Energy of Activation Concept}

In cases where a chemical reaction step is truly rate-limiting, it is conventional to explain the slowness of such a reaction step based on an activation energy that is required to reach a defined transition state (Mills et al. 1995; Kozuch and Martin 2011). This is illustrated schematically in Fig. 3. Typical reactions that are considered in this way involve the formation of covalent bonds. For example, an activation energy of about $458 \mathrm{~kJ} / \mathrm{mole}$ is required when the adsorption of $\mathrm{H}_{2}$ onto copper entails dissociation of the covalent bond (Mills et al. 1995). 
In principle the scheme shown in Fig. 3 also can be used to explain factors affecting rates of desorption. Thus, the area highlighted by cyan represents the free energy of a hypothetical adsorbed state. The activation energy required to surpass the transition state leading to desorption, in such a situation, would be given by the sum of the two arrows shown in the figure.

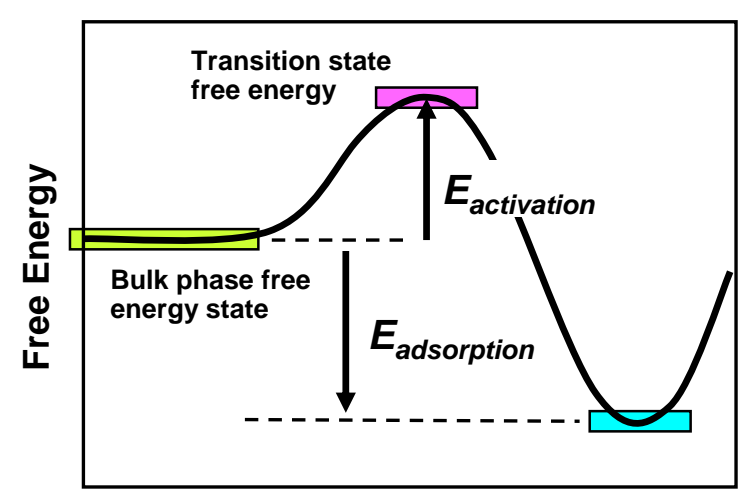

Progress of Adsorption

Fig. 3. Illustration of potential energy barrier that is often assumed to govern the progress of a chemical reaction, in which there is a transition state having less favorable energy than either the starting condition or the reacted (or bound) condition

Only a few articles were found in which activation energies were reported in the absence of proposed formation of covalent bonds. Dogan et al. (2009) reported an activation energy of $45.6 \mathrm{~kJ} \cdot \mathrm{mol}^{-1}$ for adsorption of methylene blue dye onto hazelnut shell material. Baral et al. (2006) reported $18 \mathrm{~kJ} \cdot \mathrm{mol}^{-1}$ for adsorption of $\mathrm{Cr}(\mathrm{VI})$ onto sawdust. Özer (2007) reported an activation energy of $30 \mathrm{~kJ} \cdot \mathrm{mol}^{-1}$ for the adsorption of lead ions onto wheat bran. However, in none of these cases is there a persuasive reason to expect there to be a significant energy barrier resisting the approach of the solute to sites of adsorption.

As a first step in shedding light on such processes, some researchers have used the temperature dependency of equilibrium adsorption capacities as a basis for estimating the potential energy associated with one mole of adsorption of various compounds onto cellulose-based substrates. However, as explained by Azizian et al. (2018), most reported results of such calculations have not employed dimensionless quantities, as is required by the logarithmic expressions used. To address this issue, Table 3 shows the results of dimensionally-consistent calculations based on three sets of published data dealing with physical adsorption from aqueous solution onto cellulosic materials or carbon.

To put the values in Table 3 into perspective, the average translational kinetic energy of each molecules, on a molar basis $(3 / 2 \times R T)$, is $3.7 \mathrm{~kJ} /$ mole at room temperature. Regardless of such results, many researchers have made the assumption that a good fit of adsorption data to the PSO model can be taken as evidence of chemisorption (Ho and McKay 1998c; Ho 2006a,b; Crini et al. 2007; Senthilkumaar et al. 2006; Ncibi et al. 2008; Xing and Deng 2009; Suteu et al. 2010; Nasir et al. 2018). Such assertions have been refuted (Tan and Hameed 2017). 
Table 3. Recalculated Free Energies of Adsorption Obtained from Temperature Dependence of the Adsorption Capacity in Cases that also Showed Good Fits to the PSO Model

\begin{tabular}{|c|c|c|c|c|c|}
\hline $\begin{array}{l}\text { Temperature } \\
\text { (K) }\end{array}$ & $\begin{array}{l}\Delta G_{a d}{ }^{\circ} \\
\left(\mathrm{kJmol}^{-1}\right)\end{array}$ & $\begin{array}{l}\Delta H_{a d}^{\circ} \\
\left(\mathrm{kJmol}^{-1}\right)\end{array}$ & $\begin{array}{l}\Delta S_{a d}^{\circ} \\
\left(\mathbf{k J m o l}^{-1} \mathbf{K}^{-1}\right)\end{array}$ & $\begin{array}{l}\text { System } \\
\text { Details }\end{array}$ & $\begin{array}{l}\text { Literature } \\
\text { Citation }\end{array}$ \\
\hline 293 & -6.71 & \multirow{3}{*}{-7.46} & \multirow{3}{*}{-0.0026} & \multirow{3}{*}{$\begin{array}{l}\mathrm{Ni}(\mathrm{II}) \text { sorption } \\
\text { onto nut shell } \\
\text { active carbon }\end{array}$} & \multirow{3}{*}{$\begin{array}{l}\text { Demirbas et al. } \\
2002\end{array}$} \\
\hline 303 & -6.69 & & & & \\
\hline 313 & -6.66 & & & & \\
\hline 303 & -12.41 & \multirow{3}{*}{-87.86} & \multirow{3}{*}{-0.249} & \multirow{3}{*}{$\begin{array}{l}\mathrm{Cu}(\mathrm{II}) \text { sorption } \\
\text { onto rubber } \\
\text { wood sawdust }\end{array}$} & \multirow{3}{*}{$\begin{array}{l}\text { Kalavathy et al. } \\
2005\end{array}$} \\
\hline 308 & -11.17 & & & & \\
\hline 313 & -9.92 & & & & \\
\hline 298 & -25.75 & \multirow{3}{*}{-27.83} & \multirow{3}{*}{-0.01} & \multirow{3}{*}{$\begin{array}{l}\text { Phenol sorption } \\
\text { onto activated } \\
\text { carbon fibers }\end{array}$} & \multirow[t]{3}{*}{ Liu et al. 2010} \\
\hline 313 & -25.62 & & & & \\
\hline 328 & -25.43 & & & & \\
\hline
\end{tabular}

An inherent problem with models based on chemical reaction as a rate-limiting step in typical adsorption processes is that they generally consider only a "final" binding step rather than considering the likelihood of continual exchange between free and bound entities during the process of adsorption. Such interactions are well established, and in fact they form the basis for chromatographic measurements (Miyabe and Guiochon 2003). Because most of the cellulose-based adsorbent materials considered in different research projects can be expected to have relatively similar surface-chemical composition throughout their porous structure, no important differences are to be expected between a "final" site of adsorption (occupied at the end of the test period) and the surface sites occupied by an adsorbate species earlier in the adsorption process. Thus, there does not seem to be a valid reason to neglect transient adsorption from taking place in the course of the diffusion of species from the surface into the interior. Models that explicitly include transient adsorption during a process of diffusion of adsorbate into the pore structure of an adsorbent material will be considered in the next section (George and Thomas 2001; Rudzinski and Plazinski 2008; Douven et al. 2015).

Some of the earliest studies that employed the PSO relationship (Eqs. 4 and 5 presented earlier) can in fact be interpreted based on reactions involving covalent bonds. Thus, Ritchie (1977) set out to fit data related to gas adsorption onto solids by use of a generalized model involving an arbitrary reaction order $n$,

$$
\frac{\mathrm{d} \theta}{\mathrm{d} t}=\alpha(1-\theta)^{n}
$$

where $\theta$ is the fraction of occupied sites and $\alpha$ is a constant. When the exponent was set equal to 2, this expression was shown to fit data for several systems, including data from Bansal et al. (1971), who studied the rate of chemisorption of hydrogen onto carbon. In other words, the data fit well to the PSO equation. The use of an exponent of 2 can be justified in Eq. 11 if one assumes that the reaction requires dissociation of hydrogen, where the resulting adsorbed hydrogen atoms need to occupy two adjacent sites, and further that the adsorbed hydrogen atoms are able to diffuse while remaining attached to the surface (Medved and Černý 2011). The envisioned situation is depicted in Fig. 4, where adsorption is assumed to be essentially bidentate, occupying two independent adjacent sites simultaneously (Wang and Giammar 2013). 
While the PSO equation appears to be fully justified, if one accepts the stated assumptions for the system described, it is important to note that Bansal et al. (1971), as well as the other examples considered by Ritchie (1977) were considering situations in which covalent bonds were clearly involved. The early use of the PSO equation by Sobkowski and Czerwiński (1974) to fit adsorption data likewise involved a surfacefacilitated chemical reaction as well as a surface partly filled with adsorbed atomic hydrogen, analogous to Fig. 4.

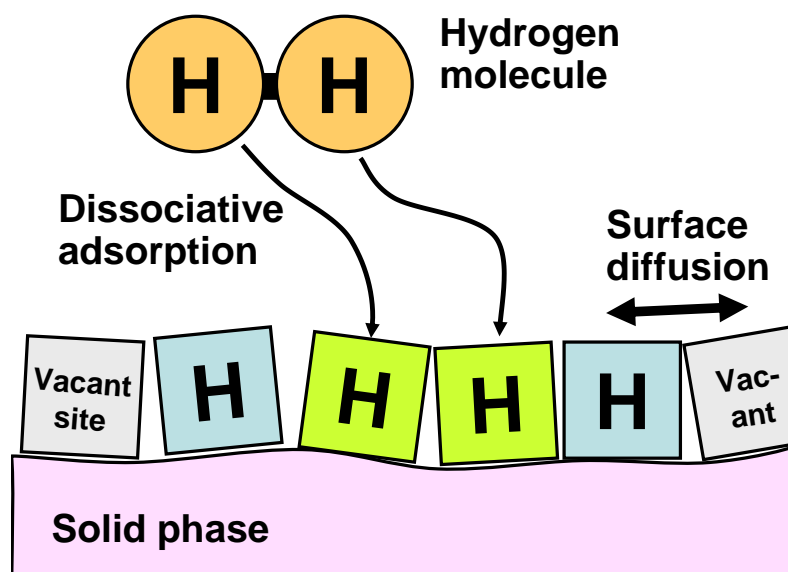

Fig. 4. Envisioned system, in which a PSO model might be justified, involving surface-catalyzed dissociation of $\mathrm{H}_{2}$ molecules, where the progress is blocked by already adsorbed $\mathrm{H}$ atoms that are free to randomly hop to adjacent adsorption sites

Though the above-mentioned studies related to hydrogen adsorption and surfacemediated dissociation reactions appear consistent with a genuine PSO-related mechanism, it should be emphasized that these gas-phase reactions represent highly specialized cases. Unlike most studies of adsorption rates from aqueous solution, the just-cited studies all clearly involved a relatively large energy of activation to break a covalent bond.

Secondly, by use of a model resembling the game "musical chairs" (see Fig. 4) it was possible to justify the possibility that vacant sites on the surface might appear to diffuse randomly, which is another requirement of the PSO model, according to traditional chemical kinetics. For essentially physical adsorption from aqueous solution onto typical porous substrates, such as cellulose-based material, neither of these special circumstances are expected.

\section{Studies Reporting Good Fits to Both Diffusion and PSO Models}

Doubts can arise when two very different explanations are being offered to account for a single phenomenon. This is especially the case when the two explanations tend to contradict each other. Specifically, such a situation has arisen in many studies that have reported excellent fits to the PSO model also have reported good fits to models based on diffusion being the rate-limiting step. For instance, the studies listed in Table 4 all reported very high coefficients of determination for the PSO model, and they also showed good fits with the diffusion-based model proposed by Weber and Morris (1963). 
Table 4. Listing of Studies Reporting Good Fits to the PSO Model and Also to Diffusion-based Systems such as the Weber-Morris Model

\begin{tabular}{|c|c|c|}
\hline Experimental system & $\begin{array}{l}R^{2} \text { value for } \\
\text { the PSO fit }\end{array}$ & Literature citation \\
\hline Methylene blue onto wheat shells & 0.997 to 0.998 & Bulut \& Aydin 2006 \\
\hline Methsufuron methyl onto volcanic soil & 0.997 to 1.000 & Caceres et al. 2010 \\
\hline $\mathrm{Cu}(\mathrm{II})$ and $\mathrm{Pb}(\mathrm{II})$ onto grafted silica & 0.999 & Chiron et al. 2003 \\
\hline $\mathrm{Mn}^{2+}$ onto biochar & 0.999 & Chowdhury et al. 2015 \\
\hline Methylene blue onto hazelnut shell & 0.999 to 1.000 & Dogan et al. 2009 \\
\hline Various studies compared & - & Douven et al. 2015 \\
\hline Methylene blue onto composite mixture & 0.995 & Liu et al. 2018 \\
\hline Malachite green onto rapeseed meal & 0.980 to 0.981 & Podstawczyk \& W. 2016 \\
\hline Dye onto jute-derived carbon & 0.991 to 0.999 & Porkodi \& Kumar 2007 \\
\hline Copper onto chitosan & 0.995 & Reddy \& Lee 2013 \\
\hline Basic dyes onto peat-resin product & - & Sun and Yang 2003 \\
\hline Basic dyes onto activated carbon & 0.999 to 1.000 & Tan et al. 2008 \\
\hline Black dye onto nanocomposites & 0.862 to $1.000 *$ & Tanzifi et al. 2018 \\
\hline Methylene blue dye onto rice husk & 0.996 to 0.999 & Vadivelan \& Kumar 2005 \\
\hline
\end{tabular}

* Note: The study by Tanzifi et al. (2018) compared four different integrated forms of the relationship for the PSO model, and quite different $\mathrm{R}^{2}$ values were obtained, as shown.

A further problematic issue is that several authors, after reporting excellent fits to the PSO model, went on to explain their data based on concepts related to diffusion-limited processes (Sun and Yang 2003; Vadivelan and Kumar 2005; Bulut and Aydin 2006; Porkodi and Kumar 2007; Tan et al. 2008; Caceres et al. 2010; Reddy and Lee 2013; Podstawczyk and Witek-Krowiak 2016; Tanzifi et al. 2018). Based partly on such problems, the review article by Plazinski et al. (2009) draws the conclusion that the PSO model does not provide a reliable indication of which mechanistic step accounts for the rate-limiting process of adsorption in a given case. In such instances, one could argue that mechanistically sound models are often more useful to analyze adsorption data, even if the coefficients of determination are lower than that of, say, a PSO model.

\section{OTHER WAYS TO ACCOUNT FOR GOOD FITS TO THE PSO MODEL}

Up to this point in the article, the focus has been on the mechanistic explanations that usually would be associated with the PSO model, involving a rate-limiting step that is second-order with respect to the available surface sites. In light of the discussion in the previous section, the main goal of this section is to answer the question, "since the PSO model itself does not appear well supported by the literature, what other explanations might reasonably account for so many excellent fits of adsorption kinetic data to the PSO equation?"

There are two main strategies that researchers have used in published works to provide an explanation for good fits of adsorption data to pseudo-second-order kinetics. The first of these sets of strategies is mathematical or statistical, arguing that the good fits are merely a consequence of how random errors can be expected to affect the analysis of data. Such an approach can be used, for instance, to assert that apparent fits to a PSO model are actually attributable to an underlying pseudo-first-order (PFO) mechanism. The PFO mechanism appears to rest on a solid theoretical foundation (Lagergren 1898). 
However, even a sound theory is valid in this case only if the surface interactions actually represent the rate-limiting step in the process. The second strategy is to look deeper into the diffusion-based theories and models of adsorption. This appears to be a very fruitful approach, given the widespread usage of the Weber-Morris (1963) system of analysis, which is based on diffusion concepts.

\section{Mathematical Issues}

Data obtained from assumed PFO model fits best to PSO model

The theoretical analysis presented by Azizian (2004) considers cases in which the initial bulk concentration of adsorbing species is either relatively low or high. By starting from the Langmuir kinetic model, it was found that when the bulk concentration is relatively high, such that it does not change significantly during the course of adsorption, good fits to the PFO (Lagergren) equation are obtained. On the other hand, when the initial bulk concentration is relatively low, such that it changes significantly during the course of adsorption, the PSO rate equation can describe the kinetics well. Thus, it was found that good fits to the PSO equation can be merely a consequence of mathematics and the selection of experimental conditions.

Another problem inherent in the PSO model, in its more commonly used forms (Blanchard et al. 1984; Ho and McKay 1998a; Ho 2014), is that it does not consider the possibility of a reverse reaction, i.e. desorption. Since almost all of the relevant studies have involved physical adsorption, rather than reactions to create covalent bonds, such neglect of desorption seems unrealistic. If both adsorption and desorption can occur, and the rates of exchange are high enough, then one can assume an equilibration between the bulk and surface sites during the whole process of adsorption. Chatterjee and Schiewer (2014) found that in cases where the initial concentration was high enough, their analysis based on continual equilibration of adsorbate molecules with surface sites was able to fit kinetic data. Azizian (2004) likewise included a desorption reaction in the analysis in an effort to develop a more realistic model while still emphasizing surface reactions during adsorption (Liu and Liu 2008).

\section{Insufficient "early" data}

A related problem, which affects many of the reported data sets that have given high values of $\mathrm{R}^{2}$ for the PSO model, is that only a few of the data points represented relatively low values of exposure time (Canzano et al. 2012). Such "early" data points are critical when attempting to discriminate between a PFO and PSO model based on goodness of fit. When not enough data are obtained at relatively low times of contact between the solution and the adsorbent, the analysis becomes more highly dependent on conditions approaching equilibrium. As already mentioned, those later times can be expected to be most affected by both (a) the fact that the PSO model does not consider a reverse reaction (desorption), and (b) the difference between the initial bulk concentration and its final value will be the largest. Canzano et al. (2012) used numerical simulation to show that such considerations can lead to good fits to the PSO model when most of the data are obtained as systems are approaching an equilibrium level of adsorption. Notably, the simulation was based on random diffusion, rather than the mechanisms implied by the PSO equation.

\section{Time-dependency reflected in both plotted axes}

In an attempt to explain why, in so many cases the PSO model has provided very good fits to data, an additional suggestion is that this is due to involvement of the time 
variable in both of the plotted axes during the fitting procedure (Canzano et al. 2012; Tanzifi et al. 2018). The suggestion is that, by using the most favorable integrated form of the PSO relationship, all the $\mathrm{R}^{2}$ values get shifted closer to 1.000. As was shown in Table 4, Tanzifi et al. (2018) obtained $\mathrm{R}^{2}$ values in the range 0.862 to 1.000 depending on which of four integrated forms of the PSO model was employed.

Canzano et al. (2012) suggested that, to minimize the influence of conditions not fitting the assumptions of the PSO model, one should omit data nearest to the equilibrium point. This is a harsh requirement, since many researchers and engineers would be interested in what happens when adsorbent material is close to saturation.

In the authors' opinion, the best method for fitting on PSO model is non-linear fitting based on non-linear form of PSO equation:

$$
q_{t}=\frac{k_{2} q_{e}^{2} t}{1+k_{2} q_{e} t}
$$

This approach is preferred because it does not include any unrealistic requirement or involvement of time variable in both plotted axes.

\section{Amplification of skewed errors (especially linearized fitting)}

Several studies have shown cases in which fits to the PSO model were highly dependent on the selection of a mathematical expression, among the forms that have been derived (Vázquez et al. 2012; Tan and Hameed 2017). As noted earlier, four different expressions can be derived by integration of the differential equation expressing the PSO relationship (Ho 2006a,b), as listed in Table A in the Appendix. Sometimes the alternative expressions can give good agreement regarding the fitting parameters, even if the $\mathrm{R}^{2}$ values are very different (Tanzifi et al. 2018). According to Canzano et al. (2012), the use of a linearized integrated form of the PSO relationship tends to give the greatest amplification of the effects of random errors, often giving rise to unmerited agreement with experimental data.

\section{A flexible equation for fitting}

The term "lumping of parameters" has been used in situations where a quantifiable phenomenon appears to have a complex dependency on a set of parameters due to interactions among more than one mechanism (Cosby et al. 1985; Chatterjee and Schiewer 2014). It appears that the PSO model, considering the manner in which it is commonly employed to fit adsorption data, can fit the definition of a lumping of effects (Tan and Hameed 2017). Specifically, rather than implying a specific reaction-dependent ratelimiting mechanism, a good fit due to the PSO model can have other interpretations, including diffusion-limited rate behavior (Douven et al. 2015). Such an explanation, due to its generality, lacks the potential to differentiate among various alternative contributing mechanisms. Rather, it has been said that the PSO model can be regarded as a flexible equation capable of fitting a range of typical adsorption kinetic data (Tan and Hameed 2017). According these authors, in light of the range of possible contributions to kinetic behavior, it is futile to use PSO fit information as a sole means of drawing conclusions regarding fundamental aspects of the process, and in particular, such fits do not provide evidence of chemisorption. In theory, one way to fit data might be with a combination of PFO, PSO, and desorption mechanistic steps. However, given the fact that the PSO model by itself is already capable of delivering $\mathrm{R}^{2}$ values near to unity, it is hard to envision how 
the same data could be used to more fully understand rate behavior that can be attributed to multiple mechanistic steps.

\section{Diffusion-limited Models}

Two contrasting situations can be considered when discussing kinetic models based on diffusion mechanisms. On the one hand, as in typical covalent reactions, one envisions a process in which the reaction to form a compound (for instance, the attachment of a group to a surface) is essentially irreversible. Alternatively, one can assume that the adsorbing species can be in continual near-equilibrium with the surface, such that there is a predictable relationship between free and adsorbed populations. The discussion that follows will include an assumption that both adsorption and desorption will take place at finite rates in the course of the progress of adsorbate from the exterior surface to sites within the pore structure of the adsorbent. Thus, as will be discussed, the fraction of time during which an adsorbing species is temporarily bound to a surface sites needs to be accounted for when defining an effective diffusion constant.

\section{Fick's theories}

A basis for understanding essentially all diffusion-limited processes is provided by the fundamental equations of Fick (Fick 1855; Henriksen and Hansen 2008). Fick's first law, as expressed in Eq. 13, relates the local rate of transport of species with a gradient of concentration (Wu et al. 2009a).

$$
J=-D \frac{\mathrm{d} C}{\mathrm{~d} x}
$$

In this expression, $J$ is the flux of the species of interest at a given point, $D$ is the diffusion constant (diffusivity), $C$ is the concentration, and $x$ is the position relative to the gradient of concentration.

Though certain systems to account for adsorption have been based on just Fick's first law of diffusion, a fuller accounting requires an additional relationship (George and Thomas 2001). Fick's section law can be expressed as in Eq. 14:

$$
\frac{\partial C}{\partial x}=D \frac{\partial^{2} C}{\partial x^{2}}
$$

In a typical experimental situation, one can envision that the bulk concentration in solution will have a known concentration. When a known amount of adsorbent material is placed into such a solution at a time defined as zero, the corresponding concentration of adsorbate associated with the adsorbent material is also taken to be zero. So initially there will be a very strong gradient of concentration at the external surface of the adsorbent material. After a brief period of time, however, equilibration will have taken place with sites near the external surface, and a less-steep gradient of concentration will have progressed towards the interior of the particles of adsorbent (Rudzinski and Plazinski 2006).

One of the general expectations that follows from diffusion-limited rate behavior is that progress towards completion ought to be a function of the square-root of time (Weber and Morris 1963; Tan and Hameed 2017). However, there is another factor that needs to be considered before proceeding further. That is, Fick's laws, as expressed in Eqs. 13 and 14 , are written in such a way that they imply a diffusion constant that is independent of location. In other words, a constant value of diffusivity is assumed at a given concentration 
of adsorbant in the adjacent solution (Chatterjee and Schiewer 2014). Such an assumption makes good sense in the case of diffusion within an isotropic liquid solution. However, in the case of a porous solid, diffusion can be constrained by physical barriers (i.e. pores extending mainly in just one direction), and the effective coefficient of diffusion being reduced by the fraction of time during which the diffusion species is immobile, in its adsorbed state. Within a smaller pore, the ratio between the surface area and the solution phase volume is larger, and such a situation favors a greater proportion of time in which a solute species is in an immobilized state at the surface.

As noted by Shen and Chen (2007), diffusion tends to dominate over convection as a means of mass transfer in zones of low permeability. Outside of such zones, depending on levels of agitation, pressure-driven flow, or thermal-motivated convection, etc., solute species can migrate many times faster. Thus, the next issue to consider involves transport from bulk solution (usually assumed to be agitated) and the external surface of the grains, pellets, fibers, etc. that contain pores small enough to maintain essentially stagnant conditions within them.

\section{External diffusion through a stagnant film or sublayer}

Textbooks and articles describing ways to account mathematically for adsorption phenomena often begin by describing transport of adsorbing species from the bulk solution to an external surface across a film or boundary layer that is modeled as a stagnant layer of liquid (Boyd et al. 1947; Rudzinski and Plazinski 2008; Chatterjee and Schiewer 2014). This is illustrated schematically in the left side of Fig. 5.

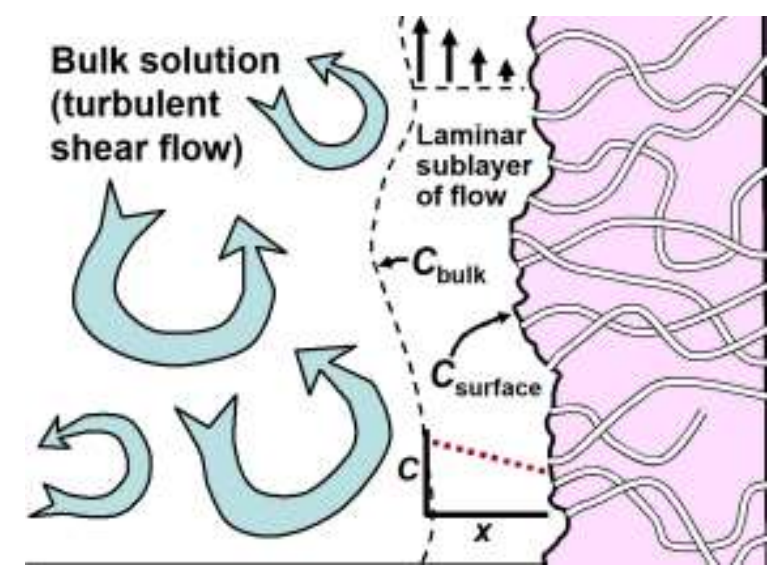

Fig. 5. Conceptual representation of a viscous sublayer at the surface of an adsorbent exposed to turbulent shear flow, such that there is a difference in the concentration of an adsorbate species between the bulk solution (at the dashed line) and at the external surface of the adsorbent

It has been shown that such transport may essentially stop if the bulk solution is unstirred (Weber and Morris 1963). In such cases, molecular diffusion by itself may be the only significant means of transport over relatively long distances, and molecular diffusion is a slow process. In view of this situation, it should not be surprising that practical systems of adsorption involve either the stirring of a suspension or the flow of solution through a packed bed. By such means, convection, which is a much more rapid mechanism of transport, can be relied upon to maintain the solute concentration near its bulk level adjacent to the particle surface. For instance, Weber and Morris (1963) demonstrated that the rate of adsorption onto porous material in a suspension depends on 
the rate of agitation only up to a certain speed of stirring, and thereafter the overall rate is independent of further increases in agitation. On the other hand, the overall rate of uptake is drastically reduced if stirring is discontinued.

Even if the bulk solution is stirred or pumped through a packed bed, there still will remain a film of liquid adjacent to the surface that can be modeled as a near-stagnant layer, such that it is reasonable to expect that transport across that layer to adsorption sites at an external surface will be governed by diffusion rather than by convection. The rate of transport in such cases, at least in the beginning, is expected to be proportional to the external surface area of the adsorbent (Chatterjee and Schiewer 2014). The cited authors concluded that processes following a pseudo-first-order rate of adsorption ought to fit well to a film-diffusion model as the rate-limiting step.

The right side of Fig. 5 represents a porous material within which diffusion is assumed to be the main mechanism of transport. In this kind of model it is assumed that any convection currents affecting the bulk of solution do not influence the interior of the adsorbate particles. Further, it usually is assumed that there is no intermittent squeezing and relaxing of the adorbate particles, which might otherwise cause flow in and out of a porous material.

Though most studies of adsorption phenomena have tended to focus on either the full process or conditions approaching equilibration or saturation, a study by Rudzinski and Plazinski (2008) concentrated on the very start of the process. A surface diffusion mechanism was found to be consistent with their data. The fact that their plots of adsorbed amount vs. square-root of time did not pass through the origin is consistent with an expectation that external surface film diffusion cannot account for the full process of adsorption. According to the theoretical analysis of Douven et al. (2015), diffusion rates associated with an external film can be expected to be important only in the very early phases of adsorption, and this factor will no longer play a significant rate-limiting role once the bulk solution has had time to equilibrate with the external surface region of the adsorbate.

\section{Diffusion along a solid surface}

The next topic, though less often mentioned in the published literature having to do with adsorption from solution onto solids (Boyd et al. 1947), will be considered at this point due to its similarity to the external boundary layer film concept just described. For the sake of the present discussion, this mechanism will be called "diffusion along a solid surface". The idea is that a solute species might be able to diffuse while remaining in contact with the surface (Alanissila and Ying 1992; Choi et al. 2001; Medved and Černý 2011). According to Choi et al. (2001) surface diffusion can account for more than $50 \%$ of mass flow rate within certain microporous adsorbents. Figure 6 is based on a concept described by Medved and Černý (2011) in which surface diffusion may involve the input of activation energy - not necessarily enough energy in each step to release the adsorbed species back into the bulk solution phase, but enough to mobilize it and allow it to randomly hop to a new location at the surface.

The surface diffusion concept has been employed as a contributing explanation in several various studies involving adsorption (Gutsche and Yoshida 1994; Maekawa et al. 1995; Choi et al. 2001). In particular, it is reasonable to expect that enzymes such as cellulase can remain attached to a cellulose surface while remaining in motion (Jervis et al. 1997; Zhang et al. 2016), though such motion may become constrained (Moran-Mirabal et al. 2013). Such systems have been discussed by Wu et al. (2009b). The surface diffusion 
mechanism can be expected to have relevance in cellulose-based systems due to the orientation of such structures as the fiber surfaces, lumen spaces, the local alignment of fibrils, and the slit-like shape of pores within cellulosic fibers after chemical pulping has removed most of the lignin. Such issues will be discussed in the final main section of this review article.
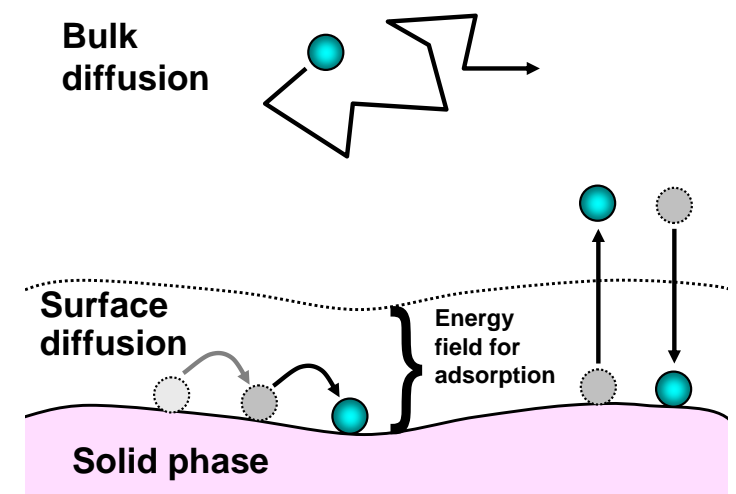

Fig. 6. Concept of surface diffusion involving a relatively low level of activation, allowing the adsorbate to hop to a random adjacent site of attachment

Crank's comprehensive diffusion-based analysis

As discussed by Rudzinski and Plazinski (2008), Chatterjee and Schiewer (2014) and Tan and Hameed (2017), one of the most complete systems to account for rates of adsorption in terms of contributing mechanisms was presented in the textbook by Crank (1956). It has been stated that other models, such as those of Weber and Morris (1963), Elovich (Piasecki and Rudzinski 2007; Liu and Liu 2008; Tan and Hameed 2017), and Boyd et al. (1947) can be regarded as restricted sub-models of the Crank analysis (Chatterjee and Schiewer 2014, see later discussion).

To summarize, the Crank model includes consideration of an external boundary layer (sometimes called surface film) diffusion step, which is assumed usually to be rapid relative to the subsequent steps of adsorption (Tan and Hameed 2017). The process of diffusion is understood to take place simultaneously with a faster exchange of adsorbing species between free and immobilized (adsorbed) states. In other words, both forward and reverse interactions with the surface are assumed to take place as the adsorbing species, on average, makes progress towards saturating the interior surfaces of the adsorbent. The Crank model is based on both Fick's first and second laws of diffusion, and thus it is able to deal with situations in which the local value of diffusivity is not constant.

As described especially in Chapter 8 of the cited work (Crank 1956), Crank assumes a fixed relationship between the local concentration $S$ of immobilized adsorbate molecules or ions at the outer surface of the pellet and the local concentration $C_{p}$ in the adjacent solution within a pore. This relationship can be expressed as,

$$
S=R C_{p}
$$

where $R$ can be regarded as a partition coefficient between the adsorbed phase and the solution phase. Adsorption is assumed to take place continuously during the diffusion process, which is assumed to follow the diffusion-based relationship, 


$$
\frac{\partial C_{p}}{\partial t}=D \frac{\partial^{2} C_{p}}{\partial x^{2}}-\frac{\partial S}{\partial t}
$$

Substitution of Eq. 15 into Eq. 16 yields:

$$
\frac{\partial C_{p}}{\partial t}=\frac{D}{R+1} \frac{\partial^{2} C_{p}}{\partial x^{2}}
$$

In this expression one can take the term $[D /(R+1)]$ as an effective value of $D$, taking account of the degree to which the rate of diffusion is slowed down by the proportion of time that the solute is immobilized on the local surfaces.

Forward and reverse reactions with the surface, i.e. adsorption and desorption, can be expressed as,

$$
\frac{\partial S}{\partial t}=\lambda C_{p}-\mu S
$$

where $\lambda$ and $\mu$ are the local rate constants for adsorption and desorption.

The validity of Crank's model is limited by the assumption of proportional adsorption, as recalled in Eq. (18). In addition, if one assumes that the amount of adsorbent is so low that the concentration of molecules in solution remains almost constant during the adsorption process, Douven et al. (2015) show that the solution of Crank's model can be written as:

$$
\frac{n(t)}{n_{e q}}=1-\frac{6}{\pi^{2}} \sum_{m=1}^{\infty} \frac{1}{m^{2}} \exp \left(-\frac{D_{e} m^{2} \pi^{2} t}{R_{p}^{2}}\right)
$$

In Eq. 19, $n(t)$ is the total number of adsorbed species at time $t, n_{e q}$ is the equilibrium value of $n$ after a long time of exposure, $m$ is the mass of adsorbent, $D_{e}$ is the effective diffusion coefficient (as affected by the fraction of time immobilized at surfaces), $R_{p}$ is the radius of adsorbent particles, and the sum over $m$ runs from one to infinity.

\section{Douven's Langmuir adsorption-desorption (LAD) analysis}

Douven et al. (2015) generalize Crank's approach by considering that adsorption is seldom conducted at concentrations so low that the surface is far from being saturated. The effect of saturation is accounted for by a Langmuir mechanism, by which the local rate of adsorption inside a pellet decreases when the concentration of immobilized species increases. This effect is absent in Eq. (18), which is equivalent to assuming proportionality between adsorbed and free molecules.

When one assumes that a Langmuir isotherm governs the adsorption process throughout a porous structure, the following equations can be used to predict the rates of adsorption and desorption,

$$
\begin{aligned}
& \frac{\partial C_{f}}{\partial t}=D \Delta C_{f}-k_{a} C_{f}\left(1-\frac{C_{a}}{C_{s a t}}\right)+k_{d} C_{a} \\
& \frac{\partial C_{a}}{\partial t}=+k_{a} C_{f}\left(1-\frac{C_{a}}{C_{s a t}}\right)-k_{d} C_{a}
\end{aligned}
$$

where $C_{f}$ is the concentration of adsorbate that is free in the pore-filling solution, $D$ is the diffusion coefficient, $\Delta$ is the Laplace operator, $k_{a}$ is the rate constant for local adsorption, $C_{a}$ is the adsorbed concentration, $C_{s a t}$ is the adsorbed saturation concentration, and $k_{d}$ is the rate constant for desorption. When time is extended to infinity, these equations imply the relationship, 


$$
\frac{C_{a}}{C_{s a t}}=\frac{C_{f}}{v C_{s a t}+C_{f}}
$$

which is just an expression of the assumed Langmuir equilibrium state.

The LAD approach proposed by Douven et al. (2015) can be regarded as an effort to apply a robust diffusion-based analysis that also takes into account reversible interactions with surface sites. A key feature of the analysis is the use of the Langmuir isotherm to mathematically describe the relationship between adsorption and the concentration of the adsorbate in the solution within each region within the system. As in Crank's (1956) analysis, Douven et al. (2015) make the assumption that both the forward and reverse interactions with the surface take place continuously as adsorbing species diffuse within pores of the adsorbent. The selection of the Langmuir isotherm for such fits can be justified based on their well-established theoretical foundation (Langmuir 1918). Also, systems of adsorbates and adsorbents that have been found to fit well to a Langmuir model generally have been judged to be promising with respect to suitability for efficient removal of various solutes from solution (Hubbe et al. 2014). Tan and Hameed (2017) noted that Douven's system can give excellent mathematical fits to data that also fit the PSO model.

A powerful aspect of the Douven et al. (2015) approach is its generality, which enables one to identify a variety of working regimes for any given adsorbate/adsorbent couple. These regimes can be identified through three dimensionless numbers: (i) an adsorption/diffusion modulus to determine whether surface reaction or diffusion is the rate limiting process (controlled by the size of the pellets); (ii) a saturation modulus to determine whether proportional or saturated Langmuir-like adsorption takes place (controlled by the concentration of the solution); and (iii) a loading modulus to determine whether the concentration of molecules in the solution decreases significantly in the course of the adsorption, or if it can be assumed to remain constant (controlled by the amount of adsorbent). In defining dimensionless parameters for such a situation, the cited work builds notably upon earlier progress achieved by Rudzinski and Plazinski (2008). It has, however, to be stressed that the dimensionless numbers defined by Douven et al. (2015) are related to the operating conditions, independently of the adsorbent material and adsorbate.

Douven et al (2015) notably show that the shape of the adsorption kinetic curves is controlled also by the operational conditions under which adsorption kinetics is being measured, in addition to the chemical nature of the adsorbent and adsorbate. This applies also to the suitability of phenomenological models such as the PFO and PSO models.

Douven et al. (2015) also established a procedure for data analysis based on evaluation of the measured "half-times" required for adsorption of half the full capacity into suspended pellets of adsorbent. For example, the PSO model is mathematically equivalent to the following equation,

$$
\frac{n(t)}{n_{e q}}=\frac{t / t_{1 / 2}}{1+t / t_{1 / 2}}
$$

where the first term is the same as in Eq. 19, and $t_{1 / 2}$ is the time required for the adsorbed amount to reach half of its equilibrium value. This equation was found to fit well to experimental data, which is consistent with the wide empirical validity of the PSO model. Based on the general LAD model, Douven et al. (2015) tabulated the values of $t_{1 / 2}$ for a variety of operational conditions identified through the three dimensionless numbers, which enables one to determine the diffusion coefficient. 


\section{Weber-Morris intra-particle diffusion analysis}

Among the diffusion-based systems of analysis, the "intraparticle diffusion" (IPD) model of Weber and Morris (1963) has been employed by far the most often for fitting of adsorption data in the case of porous materials. The following are a representative group of articles in which the Weber-Morris approach was employed to fit adsorption data (Waranusantigul et al. 2003; Suteu and Bilba 2005; Vijayaraghavan and Yun 2007; Mohan et al. 2008; Ofomaja 2008; Laohaprapanon et al. 2010; Nethaji et al. 2010; Rubin et al. 2010; Thirumalisamy and Subbian 2010). The governing equation can be expressed as,

$$
q_{t}=k_{i p d} \sqrt{t}+C
$$

where $q_{t}$ is the adsorbed amount as a function of time $(t), k_{i p d}$ is the rate constant for intraparticle diffusion, and $C$ is a constant associated with the boundary layer thickness (i.e. the "film" for the external film diffusion model). As noted, the Weber-Morris system can be regarded as a subset of the Crank analysis (Chatterjee and Schiewer 2014; Douven et al. 2015). Unlike the comprehensive approach described by Crank (1956), Weber and Morris (1963) considered only diffusion aspects, without considering how transient adsorption of the adsorbate during the process might be expected to influence the effective value of the diffusion coefficient $D$.

A characteristic feature of the Weber-Morris (1963) approach is a predicted proportionality between the adsorbed amount and the square-root of time. This squareroot relationship can be regarded as a "slowing down" of the adsorption rate in comparison to a linear, constant rate of uptake. In principle, if the adsorption data all can be described by a single line, when plotted versus the square-root of time, then the model can be taken to represent a single rate-limiting process of diffusion. In practice, such linear agreement seldom has been reported (Weber and Morris 1963). Rather, most researchers have been forced to conclude that the adsorption process, in numerous practical situations, is governed by more than one limiting mechanism - often three or more. Examples of this are provided in Table 5.

Table 5. Listing of Studies in Which Fits of Adsorption Data to the Weber-Morris Model Were Achieved by Use of Two or More Linear Segments

\begin{tabular}{|l|l|l|}
\hline Experimental system & $\begin{array}{l}\text { Number of } \\
\text { linear } \\
\text { segments }\end{array}$ & Literature citation \\
\hline Herbicide onto volcanic ash & 2 & Caceres et al. 2010 \\
\hline Acid dye onto chitosan & 3 & Cheung et al. 2007 \\
\hline Basic and acid dyes onto wood * & ca. 2 & Ho \& McKay 1998b \\
\hline Basic dye onto graphene oxide hydrogel & 3 & Liu et al. 2018 \\
\hline Dyes onto wood sawdust & ca. 1 to 2 & Ofomaja 2008 \\
\hline Copper (II) ions onto chitosan & 3 & Reddy \& Lee 2013 \\
\hline Basic dyes onto peat-resin particles & 3 & Sun and Yang 2003 \\
\hline Amido black dye on nanocomposite & $2 \& 3$ & Tanzifi et al. 2018 \\
\hline Methylene blue onto rice husk & ca. 3 & Vadivelan \& Kumar 2005 \\
\hline Reactive dye on microbial biomass * & ca. 3 & Vijayaraghavan \& Yun 2007 \\
\hline
\end{tabular}

* - These authors did not fit their data by regression. The numbers of line segments required were estimated based on appearance of the curves of uptake vs. the square-root of time.

The need to assume multiple mechanistic steps can be regarded as a weakness of this approach, since none of the cited articles made any effort to suggest the nature of these 
proposed other rate-limiting steps. In addition, the use of three or more segments of linear regression to fit a set of adsorption rate data limits the degrees of freedom in the analysis and weakens any possible conclusions, from a statistical perspective. When considering the excellent linear regression results that are often reported when presenting results from a Weber-Morris analysis, it is important to bear in mind that competing models, such as the PSO and PFO, for instance, would be expected to fit all of the data with a single expression.

A fascinating aspect of the experimental work considered by Weber and Morris (1963), who studied adsorption of alkylbenzene sulfonate onto activated carbons, is that allowing the adsorbent to "rest", which consisted for stopping the agitation for a period of 12 hours, appeared to restore an extra increment of adsorption capacity and corresponding higher rates of adsorption, compared to the same conditions without a rest period. These findings suggested to the researchers that the passage of time, without flow to facilitate a lot of fresh arrival of adsorbing species at the outer surface, allows for a net diffusion of solute farther into the interior of a fine network of pores. Also it was observed that adsorption continued almost linearly for many hours. Such issues may be important for various cellulose-based adsorbent materials, since they might influence whether there is a sufficient time of contact provided, in a given situation, to take advantage of the majority of the available adsorption capacity.

\section{Boyd analysis}

The kinetic analysis introduced by Boyd et al. (1947) can be regarded as a limiting case of the Crank analysis just discussed (Chatterjee and Schiewer 2014; Tan and Hameed 2017). The Boyd analysis, as commonly applied, provides a plotting procedure by which researchers can determine whether or not external diffusion from the bulk of solution plays a significant rate-limiting effect on the net adsorption (Vadivelan and Kumar 2005; Porkodi and Kumar 2007). In particular, the rate constant for external diffusion was plotted as a linear function of flow velocity adjacent to the surfaces.

Mechanisms considered by Boyd et al. (1947) were limited to (a) external diffusion through a film or boundary layer from the bulk of solution to the external surface of an adsorbent, (b) a pseudo-first-order ion-exchange interaction, and (c) diffusion through interior of the adsorbent material. Step (c) is essentially the approach of Weber and Morris (1963), as already discussed. Based on a combination of theoretical and experimental findings, Boyd et al. (1947) concluded that their data could be best explained in terms of just the two diffusion-based mechanisms. However, as noted by Liu and Liu (2008), the time-dependencies of the PFO model and the intraparticle diffusion mechanism were not sufficiently different to enable Boyd et al. (1947) to distinguish between them based on kinetic data. Boyd et al. (1947) observed that above a critical concentration the rate of adsorption in the system they studied appeared to be governed by intraparticle diffusion, whereas below that critical concentration the rate of adsorption was more affected by external diffusion.

\section{Elovich analysis}

The Elovich equation, which was originally presented by Roginsky and Zeldovich in 1934 (Liu and Liu 2008), can be expressed as,

$$
\frac{\mathrm{d} q}{\mathrm{~d} t}=a_{E} e^{-\alpha_{E} q}
$$


in which $a_{E}$ and $\alpha_{E}$ are constants. A derivation of the Elovich equation also was provided by Piasecki and Rudzinski (2007), who indicated that the Elovich equation followed from their "statistical rate theory". Basically, the Elovich model predicts an exponential decline in the rate of adsorption with time. Notably, the exponential term depends not only on time but also on the amount of adsorption at time $t$. This inclusion of the quantity $q$ within the exponential term results in a predicted acceleration of the decrease in rate of adsorption, especially at low values of $t$ when $q$ would be expected to be increasing more rapidly. Douven et al. (2015) called the term $\alpha_{E}$ a "slowdown parameter." Chowdhury et al. (2015) reported data for adsorption of manganese ions on biochar that appeared to fit both the PSO equation and the Elovich equation. Other researchers finding good fits to the Elovich equation include Ho and McKay (1998c), Aretxaga et al. (2001), and Caceres et al. (2010). As the Elovich equation leads to a logarithmic growth of the amount of adsorbed molecules with time, it will never lead to a saturated condition. Therefore it can be regarded as an empirical model that describes just a part of the adsorption process.

\section{Concept of a distribution of $D$ values}

A key limitation in the approaches that have been employed so far to predict adsorption rates based on diffusion models is that none of them have dealt explicitly with the heterogeneity of pore sizes in real adsorbents (Tan and Hameed 2017). The issue of heterogeneity in the local or time-dependent value of the diffusion constant $D$ was already mentioned by Crank (1956) as a possibility. In principle, when there is significant affinity between a solute and the surfaces of an adsorbent, the effective value of $D$ will decrease strongly with decreasing pore size (Douven et al. 2015). Thus, to make a convincing case to support a proposed rate expression, it would be desirable to be able to incorporate realistic estimates of the pore structure, including distributions of length of different sizes of pores. For instance in the case of water-swollen kraft fibers, one could assume (a) diameters and lengths of spaces between fibers in a pad, (b) pit opening sizes, (c) lumen diameters and lengths, (d) diameters and lengths of the larger mesopores in the cell walls, and (d) any further possible assumptions about either micropores or the possibility that the adsorbate species are able to diffuse through gel-like phases. Such a heterogeneous nature of pores in real materials, when viewed in the context of chromatography (Miyabe and Guichon 2003), would be expected to spread out the data, resulting in a long "tail" of very slow additional adsorption at very long times. Given the ever-increasing power of modern computers, rather than attempting to find integrated forms of rate expressions that can incorporate the complexities of diffusion and adsorption within realistic porous materials, it is suggested that researchers consider use of finite-element analysis and/or stochastic simulations to fit more complete diffusion models (e.g. as described by Crank 1956) to realistic estimates of pore structure in future work. Such approaches will be considered in the final main section of this article.

\section{Reptation concepts}

The term "reptation" can be defined as the snake-like motion of a chain-like polymer molecule within the constraints imposed by adjacent matter, which can include other polymer molecules (de Gennes 1971; Teraoka et al. 1992; Wu et al. 2009b; Hubbe et al. 2012a). Diffusion processes can be very slow when they require reptation (Wolterink et al. 2006; Wang and Luo 2007; Nam et al. 2010). Related phenomena can be expected in cases where pore sizes are sufficiently small that the adsorbing species are able to diffuse 
further down a passage only by changing their molecular conformation. Even greater slowing down of progress into a network of very fines pores can be expected in cases where the adsorbing species has to proceed one-by-one down a narrow pore leading further into the adsorbent material (Kabanov et al. 1989).

\section{WHAT FITS TO PSO REVEAL ABOUT CELLULOSIC MATERIALS}

This section of the article reviews published work to consider two possibilities. The first is to consider what is known about the pore structure of cellulosic materials. Such information may provide a basis for putting together a realistic model for mathematical simulation of diffusion in the pore structures of selected cellulose-based adsorbent materials. A second possibility is to consider factors for future experimental and simulation research related to the kinetics of permeation and adsorption into cellulosebased materials.

\section{Deceleration of Adsorption Rates and What It Means}

The word deceleration, for purposes of the present discussion, will mean that the rate of uptake slows down more rapidly that would be expected if the rate-limiting step involved the likelihood of collisions of adsorbing species with unoccupied sites at the surface of the adsorbent. In other words, "deceleration" will be taken to mean that the rate of uptake slows down with time to a significantly faster degree than would be expected based on the assumption of a pseudo-first-order (PFO) model (Douven et al. 2015). Some of the alternative ways in which such a deceleration in the adsorption rate can be expressed, as already reviewed in this article, include the PSO model (Blanchard et al. 1984; Ho and McKay 1998a,b,c; Ho 2006a,b) and a slowing-down factor in the Elovich equation (Douven et al. 2015). Of the factors already considered in this review article, two types of factors stand out as likely ways to explain the relatively strong deceleration of rates of adsorption with time, such that data more often agrees better with the PSO model than the PFO model. The two competing or contributing explanations are (a) significant depletion of the bulk concentration during a batch adsorption experiment, and (b) the requirement for longer periods of time for adsorbing species to diffuse to remote locations deep within a network of fine pores.

\section{Deceleration of adsorption due to depleting of the bulk concentration}

Azizian (2004) showed that both PFO and PSO equations can be derived from the Langmuir rate of equation. Based on this approach for derivation of the PSO equation, if the bulk concentration decreases, a deceleration of the adsorption rate is observed. The issue to consider at this point is to what degree this problem may affect researchers' ability to use adsorption data in an attempt to understand cellulose-based materials.

A different problem arises if one attempts to overcome such problems just by increasing the initial bulk concentration. If the initial concentration is too high, then there will be a greater contribution of random error. Errors are amplified when subtracting two relatively large numbers (the initial and final concentration in the bulk) to be able to determine a smaller quantity (the amount that becomes adsorbed). The adsorbed amount is calculated using an expression such as,

$$
S=\left(C_{o}-C_{f}\right) V / A
$$


where $S$ is the amount of adsorbed species per using area, $C_{o}$ is the initial solution concentration, $C_{f}$ is the final solution concentration, $V$ is the volume of solution, and $A$ is the area of adsorbate.

Another way to approach the situation is by numerical solution of the differential expressions, i.e. Eqs. 1 and 4. Here, since the integration has not yet been done, no assumptions have yet been made regarding the bulk concentration. The bulk concentration can be modeled using an expression such as,

$$
C_{o}-C_{t}=S_{t}(A / V)
$$

where $C_{t}$ is the bulk concentration at an arbitrary time $t$ and $S_{t}$ is the adsorbed amount per unit area at time $t$.

\section{Deceleration of adsorption due to increasing time to reach more remote pores}

The second principal way to account for a deceleration of the rate of uptake, compared to the predictions of the PFO relationship, takes note of the fine pores and lack of convective flow within particles in a typical experimental or practical case of adsorption from solution. Whether or not the adsorbing species needs to undergo a reaction with the surface at the ultimate site of adsorption, there is no escaping the fact that to reach that position it must first diffuse either through the liquid or by surface-diffusion.

By contrast, it is not hard to visualize rapid interactions with the surface, in effect escaping from the necessity to regard this is a factor limiting the overall rate of adsorption. There are two aspects to this. First, as mentioned earlier, most of the situations of interest involve physical adsorption rather than the formation of covalent bonds. Accordingly, there is no reason to require a significant activation energy affecting the ultimate

attachment. Second, there is likely to be a high ratio of surface area to solution volume within fine pores of the adsorbent. Any adsorbing entities present within the solution phase within a fine pore will be able to "try and try again," maybe many times per second, to occupy adsorption sites at the surface.

Still considering the situation of an adsorbing entity within a tiny pore, deep within a cellulose-based adsorbent material, the high ratio or local surface area to solution phase will favor a high ratio of adsorbed entities, which implies a slowing down of the rate of progress. Factors that can further retard progress of achieving equilibrium saturation within the depths of a fine porous network can involve (a) charge repulsion between adsorbing species in the solution phase and an adsorbed one that is in the way of the first, or (b) physical blockage of the fine pore by an adsorbing species, blocking the progress of another one. The problem with such concepts is that they demand one to know a great deal about the details of pore morphologies within the nanostructure of the adsorbent. The next subsection considers how such information can be obtained, as well as some of the findings in the case of cellulose-based materials.

\section{Linear lengths of pore structures within cellulose-based sorbent materials}

The maximum lengths of pores structures, as listed in Table 6, are based on straightline distances and known morphology. The lengths and diameters of fiber lumens shown in the table are as reported by Parham and Gray (1982) for the most-used species of wood. The length of a mesopore is merely an expression of half the thickness of a typical cell wall of a kraft fiber. The reason for selecting that distance, rather than the lengths of pores extended in the axial direction of fibers, is that much greater resistance to diffusion can be 
expected in the radial direction (Flynn 1995; Hansmann et al. 2002). The likely length of typical micropores within the cell walls of kraft fibers, depending on the level of refining, is expected to be substantially less than the thickness of a cell wall due to internal delamination of fibers due to such processes as swelling and refining (Molin and Daniel 2004).

Table 6. Estimates of Predominant Pore Lengths in Water-swollen, Chemically Pulped Wood Fibers, Activated Carbons, and Wood

\begin{tabular}{|l|l|l|}
\hline Specimen type & $\begin{array}{l}\text { Pore } \\
\text { length }\end{array}$ & Citation \\
\hline Chemical pulps - lumen spaces (hardwood species) & $1 \mathrm{~mm}$ & Parham \& Gray 1982 \\
\hline Chemical pulps - lumen spaces (softwood species) & $3 \mathrm{~mm}$ & Parham \& Gray 1982 \\
\hline Chemical SW pulps - mesopores (half cell wall thickness) & $0.5-1 \mu \mathrm{m}$ & Watanabe et al. 2000 \\
\hline Chemical SW pulps - mesopores (half cell wall thickness) & $0.5-4 \mu \mathrm{m}$ & Brandstrom 2001 \\
\hline Chemical pulps - micropores (<< cell wall thickness) & less & - \\
\hline Granular activated carbons - mesopore (half particle size) & $>400 \mu \mathrm{m}$ & Perlach 1981 \\
\hline Powder activated carbons - mesopores (half particle size) & $>74 \mu \mathrm{m}$ & Perlach 1981 \\
\hline Activated carbons - micropores (<< typical particle size) & less & - \\
\hline Wood strands (in oriented strand board, OSB, thickness) & $0.3-0.7 \mathrm{~mm}$ & Irle \& Barbu 2010 \\
\hline Wood particles (in particleboard: thickness; length) & $<10 ; 60 \mathrm{~mm}$ & Irle \& Barbu 2010 \\
\hline Wood - lumen spaces (hardwood species) & $1 \mathrm{~mm}$ & Parham \& Gray 1982 \\
\hline Wood - lumen spaces (hardwood species) & $3 \mathrm{~mm}$ & Parham \& Gray 1982 \\
\hline Wood - micropores & less & - \\
\hline
\end{tabular}

The lengths of pores within wood can be estimated following similar principles. However, some key differences can be highlighted. In intact wood, the adjacent fibers are firmly bound together by a dense matrix of lignin and hemicellulose. The cell walls of wood likewise contain a higher density of solid matter, since there has been no removal of lignin. On the other hand, wood shares with kraft fibers a tendency to swell to some degree upon saturation with water.

The following sources have provided some information about the pores in typical wood specimens (Flynn 1995; Hansmann et al. 2002). One of the big uncertainties when attempting to model adsorption onto particles of wood is any tendency for the inherent structure to be torn open as the material is being converted to particulate form, as in the case of sawdust or ground wood material.

The length information in the case of activated carbon samples is again based on the reported dimensions of available powder products (Perlach 1981). It is reasonable to expect that the most effective grades of activated carbon will contain a diverse range of pores. The larger of them (perhaps the larger mesopores) will have a main job of allowing adsorbing species to reach interior regions, whereas the smaller of them (perhaps mainly micropores), will have the job of providing a very high surface area.

\section{Diameters of pores within cellulose-based adsorbent materials}

Table 7 shows some estimates of pore diameters within water-swollen kraft fibers, activated carbons, and wood based on various test methods. Determination of pore size is most often carried out by gas adsorption onto the dried materials, using the BET theory (Kaneko 1994). 
Table 7. Estimates of Predominant Pore Diameters in Water-swollen, Chemically Pulped Wood Fibers, Activated Carbons, and Wood

\begin{tabular}{|c|c|c|c|}
\hline Specimen type & $\begin{array}{l}\text { Analysis } \\
\text { method }\end{array}$ & $\begin{array}{l}\text { Pore } \\
\text { diameter } \\
(\mathrm{nm})\end{array}$ & Citation \\
\hline \multicolumn{4}{|l|}{ Chemical Pulp Fibers } \\
\hline Review of various work, chemical pulps & $\begin{array}{l}\text { Polyelec- } \\
\text { trolytes }\end{array}$ & $\begin{array}{l}100 \\
\& \text { ca. } 1\end{array}$ & Alince 2002 \\
\hline $\begin{array}{l}\text { Thermomechanical pulp (spruce) } \\
\text { Unbleached kraft pulp (spruce) } \\
\text { Bleached kraft pulp (spruce) }\end{array}$ & $\begin{array}{l}\text { Solute } \\
\text { exclusion, } \\
\text { pullulans }\end{array}$ & $\begin{array}{l}0 \text { to } 3 \\
0.5 \text { to } 7 \\
1 \text { to } 10\end{array}$ & $\begin{array}{l}\text { Berthold \& Salmén } \\
1997\end{array}$ \\
\hline Wheat straw, soda-AQ pulp, freeze-dried & BET & 2.5 to 6.3 & Chen et al. 2010 \\
\hline Unspecified kraft pulps & NMR & 11 to 17 & Forsström et al. 2005 \\
\hline Bleached softwood kraft & NMR & 8 to 18 & Li et al. 1993 \\
\hline Bleached pine kraft & $\begin{array}{l}\text { Solute } \\
\text { exclusion }\end{array}$ & 2 to 200 & Stone \& Scallan 1968 \\
\hline Pine and birch kraft pulps & NMR & $\begin{array}{l}11 \text { to } 17 \\
\& \text { ca. } 1\end{array}$ & Suurnäkki et al. 1997 \\
\hline Activated Carbons & BET & $1-2000$ & Perlach 1981 \\
\hline Macropores & - & $>50$ & IUPAC definition \\
\hline Mespores & - & 2 to 50 & IUPAC definition \\
\hline Micropores & - & $<2$ & IUPAC definition \\
\hline \multicolumn{4}{|l|}{ Wood } \\
\hline Lumens, Vessels & Microscopy & $10,000+$ & Parham \& Gray 1982 \\
\hline Macropores & - & $>50$ & IUPAC definition \\
\hline Mespores & - & 2 to 50 & IUPAC definition \\
\hline Micropores & - & $<2$ & IUPAC definition \\
\hline
\end{tabular}

As can be noted in Table 7, certain researchers have detected some pores in the wood pulp fibers that appear to be in the size range of less than $2 \mathrm{~nm}$, i.e. micropores. Alince (2002) suggested that such micropores might actually be related to the non-freezing bound water, which typically can account for about $0.3 \mathrm{~g}$ per gram of water-swollen kraft fiber (Maloney et al. 1998). As an alternative to micropores, such water also may be envisioned as belonging to a hydrogel structure involving hemicellulose (Gabrielii et al. 2000).

Typical sizes of pores in commercial activated carbons are shown in Fig. 6, which is based on data in a plot from Perlach (1981). As shown, there is often a strong contrast between carbon adsorbent products intended mainly for gas adsorption and those intended for adsorption of compounds from liquid solutions. Activated carbons to be used in the gas phase mainly have micropores, i.e. pores having diameters less than about $2 \mathrm{~nm}$. By contrast, activated carbons to be used as adsorbents in liquid media often have broad pore size distributions, not limited to micropores. The idea is that such a diversity should provide a balance between high surface area (contributed especially by micropores) and relatively quick diffusion into the interior of the adsorbent grains, pellets, or fibers (contributed especially by meso- and macropores). 


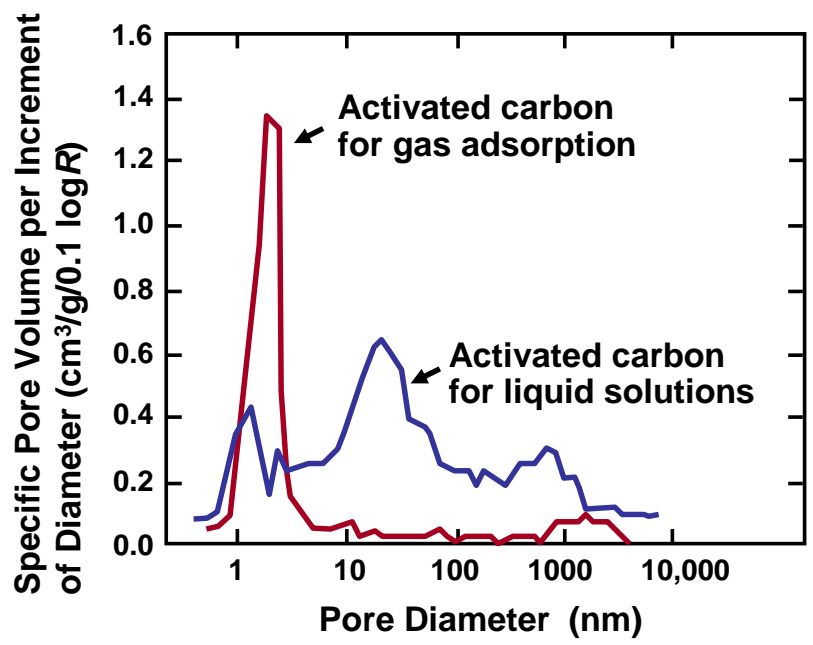

Fig. 6. Typical pore size distributions for activated carbons (based on Perlach 1981)

\section{Potential for Analysis Using a Fuller Diffusion-based Model}

In view of what is known about diffusion mechanisms and of the pore structures of cellulose-based adsorbent materials, there appear to be opportunities for carrying out more realistic numerical analyses. In particular, based on the literature it appears feasible to estimate the most predominant dimensions of pores within such adsorbent materials as activated carbons, water-swollen kraft fibers, and wood, etc. For example, it would be convenient to approximate the networks of pores within such adsorbents by models in which larger-diameter pores, having a distribution of lengths, lead to smaller-diameter pores, which also have a distribution of lengths. The diameters might be estimated, in different cases, based on the known nanostructure and by experimental methods. For example, in the case of bleached kraft fibers, the pore diameters and maximum lengths of each stage of diffusion could be estimated for (a) diffusion in the spaces between fibers, (b) diffusion within lumen spaces within fibers, (c) diffusion within mesopores in the cell walls, and (d) diffusion within micropores or within gel-like material yet deeper within fiber cell walls.

Figure 1, near the start of this article, provided a simplified, schematic concept in which diffusion into a porous material can be envisioned as a series of larger pores branching at distributed locations into a narrower class of pores, which have a distribution of branches into yet smaller pores. These might correspond to lumens or spaces between fibers in a mat of kraft fibers leading to mesopores in the cell walls, and then leading to micropores in the cell walls. Or in the case of activated carbon, they could correspond to spaces between particles in a packed bed, mesopores in the particles, and micropores branching in distributed fashion from the mesopores. Data from Tables 6 and 7, together with any other morphological information that may be available, would then complete the structural model.

Following from the descriptions of pore size distributions in cellulose-related materials (e.g. kraft fibers, activated carbon, wood, etc.), a case often can be made to model adsorption in terms of a series of stages. This concept is illustrated in Fig. 7. 


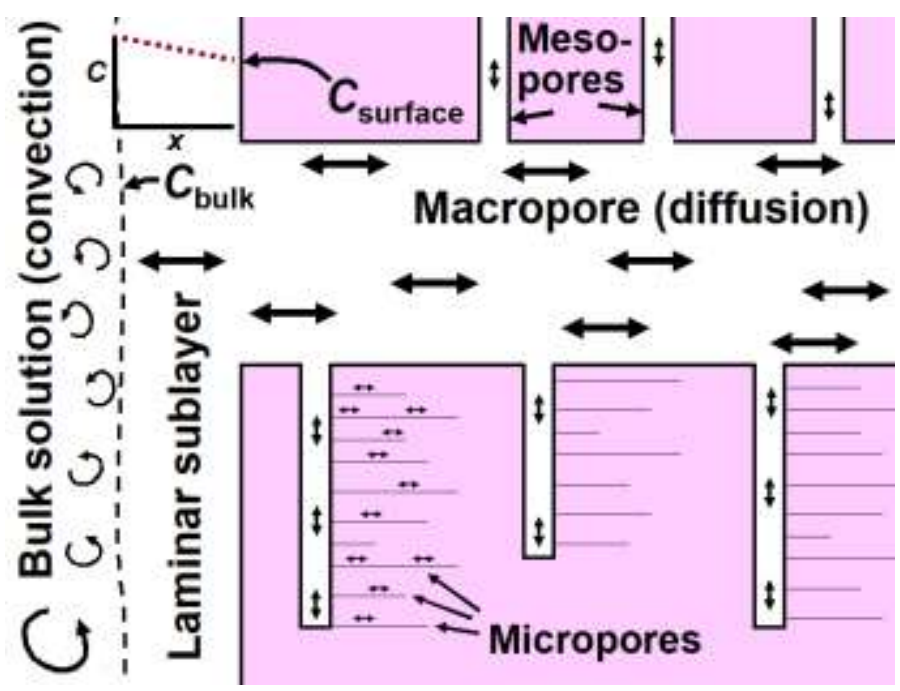

Fig. 7. Scheme to justify a stage-wise diffusion model. As described in the next section, the effective diffusion constant is likely to be significantly lower as pores become smaller.

The model depicted in Fig. 7 is set up with the following features:

A. Convective mixing (e.g. turbulent flow) in the bulk phase of solution outside of the laminar sublayer; the concentration of adsorbate is assumed to be uniform within the bulk solution.

B. Diffusion transport within the laminar boundary layer adjacent to the adsorbent material. The concentration of adsorbate is often modeled as decreasing in a linear fashion within this layer.

C. Diffusion within macropores (e.g. small spaces between fibers, lumen spaces within fibers, large pores). The adsorbate is assumed to equilibrate with the surface during the course of diffusion. Mesopores branch from the macropores at either random or evenly spaced intervals.

D. Diffusion within mesopores (e.g. cell wall or activated carbon spaces having diameters in the range 2 to $50 \mathrm{~nm}$ ). Again, the adsorbate is assumed to equilibrate with the surface during the course of diffusion. Micropores branch from the macropores at either random or evenly spaced intervals.

E. Diffusion within micropores (e.g. cell wall or activated carbon spaces having diameters less than $2 \mathrm{~nm}$ ). Again, the adsorbate is assumed to equilibrate with the surface during the course of diffusion.

Within the scheme just presented, it is to be assumed that within each region the adsorbate is undergoing continual equilibration with surface sites. This is illustrated in Fig. 8 , which envisions a stagnant solution within macropore spaces, including fiber lumens and small spaces between fibers in a wet mat of pulp. 


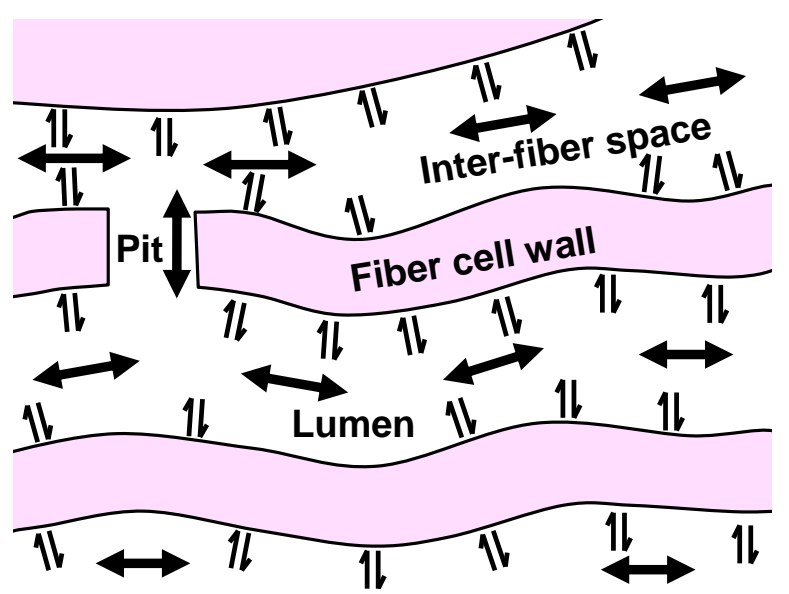

Fig. 8. Concept of simultaneous diffusion (represented by bold, two-ended arrows) and reversible adsorption (represented by equilibration symbols) during the permeation of an adsorbent into the spaces between fibers and lumen spaces (assumed to be essentially stagnant in this example)

\section{Effective diffusion constant}

The next step to consider may involve estimation of an effective diffusion constant pertaining to the rate of progress of the adsorbate through different regions of the adsorbent, i.e. lumens vs. smaller pores. Already it has been mentioned how the systems of Crank (1947) and Douven et al. (2015) deal with this issue - based on a partition coefficient or Langmuir isotherm, respectively.

In addition, an adjustment to the value of the parameter $D$ could be used to account for the fact that a given pore structure might twist and turn, rather than proceeding straight into the interior of the adsorbent. In other words, an adjustment in the effective value of $D$ can be used to account for the effect of tortuosity (Vanbrakel and Heertjes 1974; Epstein 1989; Leyvaramos and Geankoplis 1994; Shen and Chen 2007; Wu et al. 2009b). Heterogeneity of pore size is another factor that is likely to be play a large, but hard to quantify role in constraining the overall rate of diffusion rates and access to surfaces within porous media (Haggerty and Gorelick 1995). The cited study accounted for heterogeneity by considering an overall process of diffusion as being the sum of sequential sub-process in which the effective diffusion coefficient was not the same. They noted that some adsorbent materials can be regarded as a heterogeneous mixture, in which the mass transfer processes are not the same in different layers or "pods". Equation 28 was used by Vanbrakel and Heertjes (1974) to show the relationship between the effective diffusion coefficient and the relative pore volume $(\varepsilon)$, a constriction factor $(\delta)$, and the tortuosity (ratio of diffusion path length to straight distance into the adsorbent, $\tau$ ):

$$
D_{\text {eff }} / D=\varepsilon \delta /(\tau)^{2}
$$

Despite the simplicity of Eq. 28, it does not seem yet to have become well used as a means to account for rates of adsorption into porous materials.

\section{Affinity of adsorbate to adsorbent}

By analogy to chromatographic analysis methods, the time required for a physically adsorbing species to pass through porous materials can be expected to depend on its degree of affinity for surface sites (Tijssen et al. 1993; Miyabe and Guiochen 2003). A solute 
having little affinity for the column wall or the packing material generally will elute relatively quickly. A more strongly adsorbing species will elute more slowly. Though the situation is often different, depending on the details of the adsorption rate experiments, with the focus on the regions not experiencing a net flow of solvent, the same principle of slower progress is predicted by the analysis of Douven et al. (2015), where the degree of affinity is modeled based on a Langmuir isotherm. It follows that, in addition to depending on the sizes, tortuosity, and pinch-points within the pore structure, one should also expect adsorption rates to depend on the chemical nature of the surfaces and any forces or attraction or repulsion with the adsorbing species.

Depending on the nature of the lignocellulosic source material, as well as processes such as pulping, bleaching, solvent extraction, or chemical modification, the surfaces within cellulose-based adsorbent materials can vary greatly. Differences in affinity for water when comparing the surfaces of different lignocellulosic components can be determined by means of contact angle measurements with probe liquids (Hubbe et al. 2015). Lignin, which has a relatively high elemental proportion of $\mathrm{C}$ and $\mathrm{H}$ and a relatively low proportion of oxygen, is the most hydrophobic of the main components of biomass materials. By contrast, hemicellulose, which has an amorphous nature and an abundance of $-\mathrm{OH}$ groups, along with some carboxylic acid groups, is the most hydrophilic. The cellulose component, which has a high degree of internal-directed hydrogen bonding and crystalline nature, is intermediate with respect of its affinity for water.

\section{Charge interactions}

The negatively charged ionic groups associated with biomass, especially the hemicellulose component and some of the extractives, have great relevance to the adsorption of charged materials such as metal ions and dyes (Hubbe et al. 2011, 2012a). The subject of negatively charged groups associated with cellulosic material also had been studied (Budd and Herrington 1989; Hubbe et al. 2012b).

Adsorption of cationic substances onto predominantly negative materials often can be well described in terms of ion exchange (Boyd et al. 1947; Blanchard et al. 1984; Wågberg et al. 1988; Rengaraj and Moon 2002; Ho 2006a,b). In ideal cases the counterions on an anionic material used for ion exchange would be low-affinity monomeric species such as $\mathrm{Na}^{+}$. Such monomeric metal ions are readily displaced by cationic substances having greater affinity, such as divalent lead or copper ions (Blanchard et al. 1984; Ho 2006a,b; Piasecki and Rudzinski 2007; Hubbe et al. 2011), or cationic dyes (Sun and Yang 2003; Porkodi and Kumar 2007; Hubbe et al. 2012a). However, the acidic sites on plant materials, when in contact with natural environments, may already be associated with calcium or other divalent ions (Momoshima and Bondietti 1990; Torre et al. 1992). Divalent ions are generally less susceptible to being replaced from adsorption sites on a charged surface (Wachinski 2017). Based on this example, the initial state, in terms of counter-ions, can be expected to affect the adsorption of cationic substances onto cellulosic materials. Since this topic has not been widely studied relative to the adsorption on cellulosic materials, there is a need for research in this area.

\section{Solubility parameters}

The principles of solubility provide another framework by which to understand the relative affinity of different adsorbates onto surfaces, especially in cases where ionic charges do not play a dominant role. As discussed by Hansen (2007), the tendency of a component to dissolve in a selected solvent can be predicted by comparing the Hildebrand 
parameters (square-root of the cohesive energy density), the polarities, and the hydrogen bonding capabilities. Highest solubility is expected when all three of these characteristics are close matches between the substance of interest and a given solvent. It has been proposed that the same relationship ought to be useful when predicting relative affinities of various compounds onto surfaces (Browne and Cohen 1993; Tijssen et al. 1993; Wang and Shi 2010). However, there appears to be a need to explore whether such concepts can contribute to a fuller understanding of rates of adsorption or absorption onto or into cellulose-based materials.

\section{Reversibility}

Based on the concepts of Crank (1956) and Douven et al. (2015), one can expect there to be marked differences in rates of permeation of an adsorbate species into porous material depending on the proportion of time that the species is immobilized at surfaces. It follows that the rate of desorption and the half-life of the adsorbed state will play important roles. Though many studies have considered procedures to displace adsorbed species back into solution - usually as a means to restore the adsorption capacity of an adsorbent material - few studies have attempted to evaluate the rate constants for desorption when factors such as $\mathrm{pH}$ and ionic strength are held constant. Thus, to gain a better understanding of overall adsorption kinetics, there is a need for careful analysis of desorption rates. As one approach, tests can be undertaken in which the bulk solution is suddenly replaced with fresh solution that is initially free of the adsorbate of interest.

\section{CLOSING COMMENTS}

At the beginning of this article the question was posed about what can be learned from the fact that a great majority of typical adsorption data, including data related to cellulosic adsorbents, can be fit to a pseudo-second-order (PSO) rate expression. The first part of this review article attempted and failed to find adequate support in the literature for the usual mechanistic assumptions that would be associated with the PSO model. Those findings provided a motivation to answer the following question: "How else can one explain the preponderance of excellent fits of adsorption data to the PSO model in many published studies?" Two kinds of contributing explanations have been considered in the course of this literature review, one based on a surface reaction acting as the rate-limiting step, and the other based on a diffusion-limited mechanism. Much of the evidence points to the diffusion-based mechanism playing a dominant role in typical cases. Also, it appears that continual equilibration of adsorbate with surface sites in the course of diffusing with pores offers a more realistic account of what usually is happening.

If one makes the assumption that the ultimate attachment of adsorbing species to adsorption sites is the rate-limiting step, then the literature suggests that a pseudo-firstorder (PFO) rate would be most logical (Lagergren 1898; Douven et al. 2015). The fact that data more often fit better to a PSO rate expression implies that the rate of uptake slows down to a greater extent than one would expect based on the mere filling of adsorption sites. Of the several contributing explanations, one of the most persuasive involves the selection of experimental conditions. The adsorption rate data obtained for a process truly governed by a PFO mechanism can be expected to fit better to a PSO model if the initial pulp concentration is not high enough (Azizian 2004) and when there is a paucity of data associated with relatively short adsorption times (Canzano et al. 2012). To minimize such 
problems, while still attempting to achieve high precision, the initial bulk concentration needs to be chosen with care. Too high an initial concentration makes it harder to quantify how much solute has been adsorbed at any given time, since that quantity is usually calculated from the change in bulk concentration. But lower values become less and less consistent with the assumptions under which the PFO and PSO equations originally were derived, i.e. assuming that the bulk concentration is effectively constant.

The problems just described can be overcome if one assumes that any interactions of adsorbate and surface happen more rapidly than the unavoidable and time-consuming processes of diffusion. In particular, one can expect relatively longer times required for species to adsorb into the smallest of the pores and the pores situated deepest within the adsorbent material. Diffusion processes often can be regarded as a series of stages, including diffusion from the bulk solution across a boundary layer or film to the external surface of an adsorbent, diffusion within relatively large pores, diffusion within smaller pores, and finally within either micropores or a gel-like or solid-like material. If the adsorbate has an affinity for the adsorbent material, such affinity is expected to slow down the progress of diffusion, especially in the very small pores.

With modern computing power there will be opportunities to fit data without a need to place severe restraints on initial bulk concentrations. The pore sizes and lengths within cellulose-based and cellulose-derived (such as activated carbon) sorbents can be estimated by various means and then used as the basis to numerically fit the observed adsorption data based on quantifiable adsorption relationships, such as the Langmuir equation (Douven et al. 2015). Another challenge will be to evaluate desorption rates and/or half-life data for the adsorbed state into models to predict rates of adsorption into porous materials. Finally, there will be a challenge to quantify affinity information as a means of predicting such adsorbed half-lives into surfaces that can include cellulose, hemicellulose, and lignin (Hansen and Björkman 1998). In addition, many of the concepts explored in this review article will have application in understanding adsorption rates onto and into other kinds of porous substrates. All of these challenges can provide worthy topics for graduate thesis projects in the coming years.

\section{ACKNOWLEDGEMENTS}

The authors thank the following volunteers who read an earlier version of this document and suggested improvements: Julien Mahy, University of Liege, Department of Chemical Engineering, and Yuh-Shan Ho, Asia University, Trend Research Center, Taiwan.

\section{REFERENCES CITED}

Alanissila, T., and Ying, S. C. (1992). "Theory of classical surface diffusion," Prog. Surface Sci. 39(3), 227-323. DOI: 10.1016/0079-6816(92)90017-C

Ali, I. (2014). "Water treatment by adsorption columns: Evaluation at ground level," Separ. Purif. Rev. 43(3), 175-205. DOI: 10.1080/15422119.2012.748671

Alince, B. (2002). "Porosity of swollen pulp fibers revisited," Nordic Pulp Paper Res. J. 17(1), 71-73. DOI: 10.3183/npprj-2002-17-01-p071-073 
Alince, B., and van de Ven, T. G. M. (1997). "Porosity of swollen pulp fibers evaluated by polymer adsorption," in: The Fundamentals of Papermaking Materials, Trans. $11^{\text {th }}$ Fundamental Research Symp., Cambridge, Vol. 2, pp. 771-788.

Ancheyta Juárez, J. (2017). Chemical Reaction Kinetics: Concepts, Methods, and Case Studies, Wiley, Hoboken, NJ. DOI: 10.1002/9781119226666

Aretxaga, A., Romero, S, Sarra, M., and Vicent, T. (2001). "Adsorption step in the biological degradation of a textile dye," Biotechnol. Prog. 17(4), 664-668. DOI: $10.1021 / \mathrm{bp} 010056 \mathrm{c}$

Azizian, S. (2004). "Kinetic models of sorption: A theoretical analysis," J. Colloid Interface Sci. 276(1), 47-52. DOI: 10.1016/j.jcis.2004.03.048

Azizian, S., Eris, S., and Wilson, L. D. (2018). "Re-evaluation of the century-old Langmuir isotherm for modeling adsorption phenomena in solution," Chem. Phys. 513, 99-104. DOI: 10.1016/j.chemphys.2018.06.022

Bailey, G. W., and White, J. L. (1964). "Review of adsorption \& desorption of organic pesticides by soil colloids with implications concerning pesticide bioactivity," $J$. Agric. Food Chem. 12(4), 324-332. DOI: 10.1021/jf60134a007

Bansal, R. C., Vastola, F. J., and Walker, P. L. (1971). "Studies on ultra-clean carbon surfaces. 3. Kinetics of chemisorption of hydrogen on graphon," Carbon 9, 185-192. DOI: 10.1016/0008-6223(71)90130-8

Baral, S. S., Das, S. N., and Rath, P. (2006). "Hexavalent chromium removal from aqueous solution by adsorption on treated sawdust," Bioochem. Eng. J. 31(3), 216222. DOI: $10.1016 /$ j.bej.2006.08.003

Berthold, J., and Salmén, L. (1997). "Effects of mechanical and chemical treatments on the pore size distribution in wood pulps examined by inverse size exclusion chromatography (SEC)," J. Pulp Paper Sci. 23(6), J245-J253.

Blanchard, G., Maunaye, M., and Martin, G. (1984). "Removal of heavy metals from waters by means of natural zeolites," Water Res. 18, 1501-1507. DOI: 10.1016/00431354(84)90124-6

Box, G. E. P. (1976). "Science and statistics,” J. Amer. Statistical Assoc. 71, 791-799. DOI:10.1080/01621459.1976.10480949

Boyd, G. E., Adamson, A. W., and Myers, L. S. (1947). “The exchange adsorption of ions from aqueous solutions by organic zeolites. II. Kinetics," J. Amer. Chem. Soc. 69, 2836-2848. DOI: 10.1021/ja01203a066

Brandstrom, J. (2001). "Micro- and ultrastructural aspects of Norway spruce tracheids: A review," IAWA J. 22(4), 333-353. DOI: 10.1163/22941932-90000381

Browne, T. E., and Cohen, Y. (1993). "Polymer-grafted silica - A screening system for polymeric adsorption resin development," Indust. Eng. Chem. Res. 32(4), 716-725. DOI: 10.1021/ie00016a019

Budd, J., and Herrington, T. M. (1989). "Surface-charge and surface-area of cellulose fibers," Colloids Surf. 36(3), 273-288. DOI: 10.1016/0166-6622(89)80243-4

Bulut, Y., and Aydin, H. (2006). "A kinetics and thermodynamics study of methylene blue adsorption on wheat shells," Desalination 194, 259-267. DOI: 10.1016/j.desal.2005.10.032

Caceres, L., Escudey, M., Fuentes, E., and Baez, M. E. (2010). "Modeling the sorption kinetic of metsulfuron-methyl on Andisols and Ultisols volcanic ash-derived soils: Kinetics parameters and solute transport mechanisms," J. Hazard Mater. 179, 795803. DOI: 10.1016/j.jhazmat.2010.03.074 
Calvet, R., Terce, M., and Arvieu, J. C. (1980a). "Bibliographical review - Adsorption of pesticides by the soils and their constituents. 1. Description of the adsorption phenomenon," Ann. Agron. 31(1), 33-62.

Calvet, R., Terce, M., and Arvieu, J. C. (1980b). "Bibliographical review - Adsorption of pesticides by the soils and their constituents. 2. The factors of the adsorption," Ann. Agron. 31(2), 125-162.

Canzano, S., Iovino, P., Leone, V., Salvestrini, S., and Capasso, S. (2012). "Use and misuse of sorption kinetic data: A common mistake that should be avoided," Adsorp. Sci. Technol. 30(3), 217-225. DOI: 10.1260/0263-6174.30.3.217

Chatterjee, A., and Schiewer, S (2014). "Multi-resistance kinetic models for biosorption of Cd by raw and immobilized citrus peels in batch and packed-bed columns," Chem. Eng. J. 244, 105-116. DOI: 10.1016/j.cej.2013.12.017

Chen, Y. M., Wang, Y., Wan, J. Q., and Ma, Y. W. (2010). "Crystal and pore structure of wheat straw cellulose fiber during recycling," Cellulose 17(2), 329-338. DOI: 10.1007/s10570-009-9368-Z

Cheung, W. H., Szeto, Y. S., and McKay, G. (2007). "Interparticle diffusion processes during acid dye adsorption onto chitosan," Bioresour. Technol. 98(15), 2897-2904. DOI: $10.1016 /$ j.biortech.2006.09.045

Chiron, N., Guilet, R., and Deydier, E. (2003). "Adsorption of $\mathrm{Cu}(\mathrm{II})$ and $\mathrm{Pb}$ (II) onto a grafted silica: Isotherms and kinetic models," Water Res. 37(13), 3079-3086. DOI: 10.1016/S0043-1354(03)00156-8

Choi, J. G., Do, D. D., and Do, H. D. (2001). "Surface diffusion of adsorbed molecules in porous media: Monolayer, multilayer, and capillary condensation regimes," Ind. Eng. Chem. Res. 40(19), 4005-4031. DOI: 10.1021/ie010195z

Chowdhury, Z. Z., Hasan, M. R., Abd Hamid, S. B., Samsudin, E. M., Zain, S. M., and Khalid, K. (2015). "Catalytic pretreatment of biochar residues derived from lignocellulosic feedstock for equilibrium studies of manganese, $\mathrm{Mn}$ (II) cations from aqueous solution,” RSC Advan. 5(9), 6345-6356. DOI: 10.1039/c4ra09709b

Coleman, N. T., McClung, A. C., and Moore, D. P. (1956). "Formation constants for Cu(II)-peat complexes," Science 123, 330-331. DOI: 10.1126/science.123.3191.330

Connors, K. E. (1990). Chemical Kinetics. The Study of Reaction Rates in Solution, VCH, New York, NY.

Cosby, B. J., Hornberger, G. M., Galloway, J. N., and Wright, R. F. (1985). "Modeling the effects of acid deposition - Assessment of a lumped parameter model of soil-water and streamwater chemistry," Water Resour. Res. 21(1), 51-63. DOI: 10.1029/WR021i001p00051

Crank, J. (1956). The Mathematics of Diffusion, Oxford Univ. Press, London.

Crini, G., Peindy, H. N., Gimbert, F., and Robert, C. (2007). "Removal of CI Basic Green 4 (Malachite Green) from aqueous solutions by adsorption using cyclodextrinbased adsorbent: Kinetic and equilibrium studies," Separ. Purif. Technol. 53(1), 97110. DOI: 10.1016/j.seppur.2006.06.018

de Gennes, P. G. (1971). "Reptation of a polymer chain in presence of fixed obstacles," J. Chem. Phys. 55, 572-579. DOI: 10.1063/1.1675789

Demirbas, A. (2008). "Heavy metal adsorption onto agro-based waste materials: A review," J. Hazard. Mater. 157, 220-229. DOI: 10.1016/j.jhazmat.2008.01.024

Demirbas, E., Kobya, M., Oncel, S., and Sencan, S. (2002). "Removal of Ni(II) from aqueous solution by adsorption onto hazelnut shell activated carbon: Equilibrium studies," Bioresour. Technol. 84(3), 291-293. DOI: 10.1016/S0960-8524(02)00052-4 
Denisov, E. T., Sarkisov, O. M., and Likhtenschtein, G. I. (2003). Chemical Kinetics. Fundamentals and New Developments, Elsevier, Amsterdam.

Do, D. D., and Do, H. D. (2003). "Pore characterization of carbonaceous materials by DFT and GCMC simulations: A review," Adsorp. Sci. Technol. 21(5), 389-423. DOI: 10.1260/026361703769645753

Dogan, M., Abak, H., and Alkan, M. (2009). "Adsorption of methylene blue onto hazelnut shell: Kinetics, mechanism and activation parameters," J. Hazard. Mater. 164(1), 172-181. DOI: 10.1016/j.jhazmat.2008.07.155

Doktorov, A. B., and Kipriyanov, A. A. (2007). "Deviation from the kinetic law of mass action for reactions induced by binary encounters in liquid solutions," J. Phys. Condensed Matter 19(6), article no. 065136. DOI: 10.1088/0953-8984/19/6/065136

Douven, S., Paez, C. A., and Gommes, C. J. (2015). "The range of validity of sorption kinetic models," J. Colloid Interface Sci. 448, 437-450. DOI: 10.1016/j.jcis.2015.02.053

Epstein, N. (1989). "On tortuosity and the tortuosity factor in flow and diffusion through porous-media," Chem. Eng. Sci. 44(3), 777-779. DOI:10.1016/0009-2509(89)85053-5

Fick, A. (1855). "Ueber Diffusion," Annalen de Physik 170(1), 59-86. DOI: 0.1002/andp.18551700105

Forsström, J., Andreasson, B., and Wågberg, L. (2005). "Influence of pore structure and water retaining ability of fibres on the strength of papers from unbleached kraft fibres," Nordic Pulp Paper Res. J. 20(2), 176-185. DOI: 10.3183/npprj-2005-20-02p176-185

Flynn, K. A. (1995). "A review of the permeability, fluid-flow, and anatomy of spruce (Picea spp.)," Wood Fiber Sci. 27(3), 278-284.

Gabrielii, I., Gatenholm, P., Glasser, W. G., Jain, R. K., and Kenne, L. (2000). "Separation, characterization and hydrogel-formation of hemicellulose from aspen wood," Carbohydr. Polym. 43(4), 367-374. DOI: 10.1016/S0144-8617(00)00181-8

George, S. C., and Thomas, S. (2001). "Transport phenomena through polymeric systems," Prog. Polym. Sci. 26(6), 985-1017. DOI: 10.1016/S0079-6700(00)00036-8

Gupta, V. K., and Suhas (2009). "Application of low-cost adsorbents for dye removal A review," J. Environ. Manag. 90(8), 2313-2342. DOI: 10.1016/j.jenvman.2008.11.017

Gutsche, R., and Yoshida, H. (1994). "Solid diffusion in the pores of cellulose membrane," Chem. Eng. Sci. 49(2), 179-188. DOI: 10.1016/0009-2509(94)80036-7

Haerifar, M., and Azizian, S. (2013). "Mixed surface reaction and diffusion-controlled kinetic model for adsorption at the solid-solution interface," J. Phys. Chem. C 117(16), 8310-8317. DOI: 10.1021/jp401571m

Haggerty, R., and Gorelick, S. M. (1995). "Multiple-rate mass transfer for modeling diffusion and surface reactions in media with pore-scale heterogeneity," Water Resour. Res. 31(10), 2383-2400. DOI: 10.1029/95WR10583

Hameed, B. H., Din, A. T. M., and Ahmad, A. L. (2007). "Adsorption of methylene blue onto bamboo-based activated carbon: Kinetics and equilibrium studies," J. Hazard. Mater. 141(3), 819-825. DOI: 10.1016/j.jhazmat.2006.07.049

Hansen, C. M. (2007). Hansen Solubility Parameters: A User's Handbook, $2^{\text {nd }}$ Ed., CRC Press, Boca Raton, FL, USA. DOI: 10.1201/9781420006834

Hansen, C. M., and Björkman, A. (1998). "The ultrastructure of wood from a solubility parameter point of view," Holzforschung 52(4), 335-344. DOI:

10.1515/hfsg.1998.52.4.335 
Hansmann, C., Wimmer, W. G. R., and Teischinger, A. (2002). "Permeability of wood A review." Drevarky Vyskum 47(4), 1-16.

Henriksen, N. E., and Hansen, F. Y. (2008). Theories of Molecular Reaction Dynamics: The Microscopic Foundation of Chemical Kinetics, Oxford Univ. Press, New York.

Hill, C. G. (2014). An Introduction to Chemical Engineering Kinetics \& Reactor Design, Wiely, Hoboken, NJ, USA.

Ho, Y. S. (2006a). "Second-order kinetic model for the sorption of cadmium onto tree fern: A comparison of linear and non-linear methods," Water Res. 40(1), 119-125. DOI: 10.1016/j.watres.2005.10.040

Ho, Y. S. (2006b). "Review of second-order models for adsorption systems," J. Hazard Mater. 136(3), 681-689. DOI: 10.1016/j.jhazmat.2005.12.043

Ho, Y. S. (2014). "Using of 'pseudo-second-order model' in adsorption," Environ. Sci. Pollut. Res. 21(11), 7234-7235. DOI: 10.1007/s11356-013-2213-9

Ho, Y. S. (2016). "Comments on the paper 'Removal of aqueous $\mathrm{Hg}$ (II) and Cr(VI) using phytic acid doped polyaniline/cellulose acetate composite membrane'," $J$. Hazard. Mater. 311, 273-274. DOI: 10.1016/j.jhazmat.2016.01.058

Ho, Y. S., and McKay, G. (1998a). "Sorption of dye from aqueous solution by peat," Chem. Eng. J. 70(2), 115-124. DOI: 10.1016/S0923-0467(98)00076-1

Ho, Y. S., and McKay, G. (1998b). "Kinetic models for the sorption of dye from aqueous solution by wood," Process Safety Environ. Protec. 76(B2), 183-191. DOI: $10.1205 / 095758298529326$

Ho, Y. S., and McKay, G. (1998c). "A comparison of chemisorption kinetic models applied to pollutant removal on various sorbents," Process Saf. Environ. Protec. 76(B4), 332-340. DOI: 10.1205/095758298529696

Ho, Y. S., and McKay, G. (1999). "Pseudo-second order model for sorption processes," Process Biochem. 34(5), 451-465. DOI: 10.1016/S0032-9592(98)00112-5

House, J. E. (2007). Principles of Chemical Kinetics, Elesevier/Academic Press, Boston.

Hubbe, M. A., Pawlak, J. J., and Koukoulas, A. A. (2008). "Paper's appearance: A review," BioResources 3(2), 627-665.

Hubbe, M. A., Hasan, S. H., and Ducoste, J. J. (2011). "Cellulosic substrates for removal of pollutants from aqueous systems: A review. 1. Metals," BioResources 6(2), 21612287.

Hubbe, M. A., Beck, K. R., O'Neal, W. G., and Sharma, Y. C. (2012a). "Cellulosic substrates for removal of pollutants from aqueous systems: A review. 2. Dyes," BioResources 7(2), 2592-2687. DOI: 10.15376/biores.7.2.2592-2687

Hubbe, M. A., Sundberg, A., Mocchiutti, P., Ni, Y., and Pelton, R. (2012b). "Dissolved and colloidal substances (DCS) and the charge demand of papermaking process waters and suspensions: A review," BioResources 7(4), 6109-6193. DOI: 10.15376/biores.7.4.6109-6193

Hubbe, M. A. (2013). "New horizons for use of cellulose-based materials to adsorb pollutants from aqueous solutions," Lignocellulose 2(2), 386-411.

Hubbe, M. A., Park, J., and Park, S. (2014). "Cellulosic substrates for removal of pollutants from aqueous systems: A review. Part 4. Dissolved petrochemical compounds," BioResources 9(4), 7782-7925.

Hubbe, M. A., Gardner, D. J., and Shen, W. (2015). "Contact angles and wettability of cellulosic surfaces: A review of proposed mechanisms and test strategies," BioResources 10(4), 8657-8749. DOI: 10.15376/biores.10.4.Hubbe_Gardner_Shen 
Inyang, M. I., Gao, B., Yao, Y., Xue, Y. W., Zimmerman, A., Mosa, A., Pullammanappallil, P., Ok, Y. S., and Cao, X. D. (2016). "A review of biochar as a low-cost adsorbent for aqueous heavy metal removal," Crit. Rev. Environ. Sci. Technol. 46(4), 406-433. DOI: 10.1080/10643389.2015.1096880

Irle, M., and Barbu, M. C. (2010). "Wood-based panel technology," in: Wood-based Panels - An Introduction for Specialists, Thomen, H., Irle, M., and Sernek, M. (eds.), Brunel Univ. Press, Uxbridge, Ch. 1, pp. 1-94.

Jervis, E. J., Haynes, C. A., and Kilburn, D. G. (1997). "Surface diffusion of cellulases and their isolated binding domains on cellulose," J. Biological Chem. 272(38), 24016-24023. DOI: 10.1074/jbc.272.38.24016

Kabanov, V. A., Zezin, A. B., and Rogacheva, V. B. (1989). "Active transport of linear polyions in oppositely charged swollen polyelectrolyte networks," Macromol. Chem. Phys. 190, 2211-2216. DOI: 10.1002/macp.1989.021900921

Kalavathy, M. H., Karthikeyan, T., Rajgopal, S., and Miranda, L. R. (2005). "Kinetic and isotherm studies of $\mathrm{Cu}(\mathrm{II})$ adsorption onto $\mathrm{H}_{3} \mathrm{PO}_{4}$-activated rubber wood sawdust," J. Colloid Interface Sci. 292(2), 354-362. DOI: 10.1016/j.jcis.2005.05.087

Kaneko, K. (1994). "Determination of pore-size and pore-size distribution. 1. Adsorbents and catalysts," J. Membrane Sci. 96, 59-89. DOI: 10.1016/03767388(94)00126-X

Kozuch, S., and Martin, J. M. L. (2011). "The rate-determining step is dead. Long live the rate-determining state!," ChemPhysChem 12(8), 1413-1418. DOI: 10.1002/cphc.201100137

Kumar, R., Sharma, R. K., and Singh, A. P. (2017). "Cellulose based grafted biosorbents - Journey from lignocellulose biomass to toxic metal ions sorption applications - A review," J. Molecular Liquids 232, 62-93. DOI: 10.1016/j.molliq.2017.02.050

Lagergren, S. (1898). "About the theory of so-called adsorption of soluble substances," K. Sven. Vetenskapsakad. Handl. 24, 1-39.

Langmuir, I. (1918). "The adsorption of gases on plane surface of glass, mica and platinum," J. Am. Chem. Soc. 40, 1361-1403. DOI: 10.1021/ja02242a004

Laohaprapanon, S., Marques, M., and Hogland, W. (2010). "Removal of organic pollutants from wastewater using wood fly ash as a low-cost sorbent," Clean - Soil Air Water 38(11), 1055-1061. DOI: 10.1002/clen.201000105

Largitte, L., and Pasquier, R. (2016). "A review of the kinetics adsorption models and their application to the adsorption of lead by an activated carbon," Chem. Eng. Res. Design 109, 495-504. DOI: 10.1016/j.cherd.2016.02.006

Leyvaramos, R., and Geankoplis, C. J. (1994). "Diffusion in liquid-filled pores of activated carbon. 1. Pore volume diffusion," Can. J. Chem. Eng. 72(2), 262-271. DOI: $10.1002 /$ cjce.5450720213

Li, T.-Q., Henriksson, U., and Ödberg, L. (1993). "Determination of pore sizes in wood cellulose fibers by ${ }^{2} \mathrm{H}$ and ${ }^{1} \mathrm{H}$ NMR," Nordic Pulp Paper Res. J. 8(3), 326-330. DOI: 10.3183/npprj-1993-08-03-p326-330

Lin, Y., Fang, G., Deng, Y. J., Shen, K. Z., Wu, T., and Li, M. (2018). "Highly effective removal of methylene blue using a chemi-mechanical pretreated cellulose-based superabsorbent hydrogel," BioResources 13(4), 8709-8722. DOI:

10.15376/biores.13.4.8709-8722

Liu, Q.-S., Zheng, T., Wang, P., Jiang, J.-P., and Li, N. (2010). “Adsorption isotherm, kinetic and mechanistic studies of some substituted phenols on activated carbon fibers," Chem. Eng. J. 157, 348-356. DOI: 10.1016/j.cej.2009.11.013 
Liu, Y., Huang, S. B., Zhao, X. S., and Zhang, Y. Q. (2018). "Fabrication of threedimensional porous beta-cyclodextrin/chitosan functionalized graphene oxide hydrogel for methylene blue removal from aqueous solution," Colloids Surf A Physicochem. Eng. Aspects 539, 1-10. DOI: 10.1016/j.colsurfa.2017.11.066

Liu, Y., and Liu, Y. J. (2008). "Biosorption isotherms, kinetics and thermodynamics," Sep. Purif. Technol. 61, 229-242. DOI: 10.1016/j.seppur.2007.10.002

Maekawa, M., Murkami, K., and Yoshida, H. (1995). "Effects of type of adsorption isotherms on parallel diffusion of sulfonated dyes into porous cellulose membrane," Colloid Polymer Sci. 273(8), 793-799. DOI: 10.1007/BF00658759

Maloney, T. C., Paulapuro, H., and Stenius, P. (1998). "Hydration and swelling of pulp fibers measured with differential scanning calorimetry," Nordic Pulp Paper Res. 13(1), 31-36. DOI: 10.3183/npprj-1998-13-01-p031-036

Medved, I., and Cerny, R. (2011). "Surface diffusion in porous media: A critical review," Micropor. Mesopor. Mater. 142(2-3), 405-422. DOI:

10.1016/j.micromeso.2011.01.015

Mills, G., Jónsson, H., and Schenter, G. K. (1995). "Reversible work transition state theory: Application to dissociative adsorption of hydrogen," Surface Sci. 324, 305337. DOI: 10.1016/0039-6028(94)00731-4

Miyabe, K., and Guiochon, G. (2003). "Measurement of the parameters of the mass transfer kinetics in high performance liquid chromatography," J. Separ. Sci. 26(3-4), 155-173. DOI: $10.1002 /$ jssc. 200390024

Mohan, S. V., Ramanaiah, S. V., and Sharma, P. N. (2008). "Biosorption of direct azo dye from aqueous phase onto Spirogyra sp I02: Evaluation of kinetics and mechanistic aspects," Biochem. Eng. J. 38, 61-69. DOI: 10.1016/j.bej.2007.06.014

Molin, U., and Daniel, G. (2004). "Effects of refining on the fibre structure of kraft pulps as revealed by FE-SEM and TEM: Influence of alkaline degradation," Holzforschung 58(3), 226-232. DOI: 10.1515/HF.2004.035

Momoshima, N., and Bondietti, E. A. (1990). "Cation binding in wood - Applications to understanding historical changes in divalent-cation availability to red spruce," Can. J. For. Res. 20(12), 1840-1849. DOI: 10.1139/x90-247

Moran-Mirabal, J. M., Bolewski, J. C., and Walker, L. P. (2013). "Thermobifida fusca cellulases exhibit limited surface diffusion on bacterial micro-crystalline cellulose," Biotechnol. Bioeng. 110(1), 47-56. DOI: 10.1002/bit.24604

Nam, G., Johner, A., and Lee, N. K. (2010). "Reptation of a semiflexible polymer through porous media." J. Chem. Phys. 133(4), article no. 144908. DOI: $10.1063 / 1.3457999$

Nasir, A. M., Nordin, N. A. H. M., Goh, P. S., and Ismail, A. F. (2018). “Application of two-dimensional leaf-shaped zeolitic imidazolate framework (2D ZIF-L) as arsenite adsorbent: Kinetic, isotherm and mechanism," J. Molec. Liq. 250, 269-277. DOI: 10.1016/j.molliq.2017.12.005

Ncibi, M. C., Mahjoub, B., and Seffen, M. (2008). "Investigation of the sorption mechanisms of metal-complexed dye onto Posidonia oceanica (L.) fibres through kinetic modelling analysis," Bioresour. Technol. 99(13), 5582-5589. DOI: 10.1016/j.biortech.2007.10.040

Nethaji, S., Sivasamy, A., Thennarasu, G., and Saravanan, S. (2010). "Adsorption of Malachite Green dye onto activated carbon derived from Borassus aethiopum flower biomass," J. Hazard Mater. 181(1-3), 271-280. DOI: 10.1016/j.jhazmat.2010.05.008 
Ödberg, L., Tanaka, H., and Swerin, A. (1993). "Kinetic aspects of the adsorption of polymers on cellulosic fibers," Nordic Pulp Paper Res. J. 8(1), 6-9, 47. DOI: 10.3183/npprj-1993-08-01-p006-010

Ofomaja, A. E. (2008). "Kinetic study and sorption mechanism of methylene blue and methyl violet onto mansonia (Mansonia altissima) wood sawdust," Chem. Eng. J. 143(1-3), 85-95. DOI: 10.1016/j.cej.2007.12.019

Özer, A. (2007). "Removal of $\mathrm{Pb}$ (II) ions from aqueous solutions by sulphuric acidtreated wheat bran," J. Hazard Mater. 141, 753-761. DOI: 10.1016/j.jhazmat.2006.07.040

Parham, R. A., and Gray, R. L. (1982). The Practical Identification of Wood Pulp Fibers, TAPPI Press, Atlanta.

Pekar, M. (2005). "Thermodynamics and foundations of mass-action kinetics," Prog. Reaction Kinetics Mechan. 30, 3-113. DOI: 10.3184/007967405777874868

Perlach, J. R. (1981). Activated Carbon Adsorption for Wastewater Treatment, CRC Press, Boca Raton, LA, pp. 260.

Piasecki, W., and Rudzinski, W. (2007). "Application of the statistical rate theory of interfacial transport to investigate the kinetics of divalent metal ion adsorption onto energetically heterogeneous surfaces of oxides and activated carbons," Appl. Surface Sci. 253, 5814-5817. DOI: 10.1016/j.apsusc.2006.12.066

Plazinski, W., Rudzinski, W., and Plazinska, A. (2009). "Theoretical models of sorption kinetics including a surface reaction mechanism: A review," Advan. Colloid Interface Sci. 152(1-2), 2-13. DOI: 10.1016/j.cis.2009.07.009

Podstawczyk, D., and Witek-Krowiak, A. (2016). "Novel nanoparticles modified composite eco-adsorbents - A deep insight into kinetics modelling using numerical surface diffusion and artificial neural network models," Chem. Eng. Res. Design 109, 1-17. DOI: $10.1016 /$ j.cherd.2016.01.008

Porkodi, K., and Kumar, K. V. (2007). "Equilibrium, kinetics and mechanism modeling and simulation of basic and acid dyes sorption onto jute fiber carbon: Eosin yellow, malachite green and crystal violet single component systems," J. Hazard. Mater. 143, 311-327. DOI: 10.1016/j.jhazmat.2006.09.029

Reddy, D. H. K., and Lee, S. M. (2013). "Synthesis and characterization of a chitosan ligand for the removal of copper from aqueous media," J. Appl. Polym. Sci. 130(6), 4542-4550. DOI: 10.1002/app.39578

Rengaraj, S., and Moon, S. H. (2002). "Kinetics of adsorption of Co(II) removal from water and wastewater by ion exchange resins," Water Res. 36(7), 1783-1793. DOI: 10.1016/S0043-1354(01)00380-3

Ritchie, A. G. (1977). "Alternative to Elovich equation for kinetics of adsorption of gases on solids,” J. Chem. Soc. - Faraday Trans. I 73, 1650-1653. DOI: 10.1039/f19777301650

Rubin, E., Rodriguez, P., Herrero, R., and Vicente, M. E. S. (2010). “Adsorption of methylene blue on chemically modified algal biomass: Equilibrium, dynamic, and surface data," J. Chem. Eng. Data 55(12), 5707-5714. DOI: 10.1021/je100666v

Rudzinski, W., and Plazinski, W. (2006). "Kinetics of solute adsorption at solid/solution interfaces: A theoretical development of the empirical pseudo-first and pseudosecond order kinetic rate equations, based on applying the statistical rate theory of interfacial transport," J. Phys. Chem. B 110(33), 16514-16525. DOI:

10.1021/jp061779n 
Rudzinski, W., and Plazinski, W. (2008). "Kinetic of solute adsorption at solid/solution interfaces: On the special features of the initial adsorption kinetics," Langmuir 24, 6738-6744. DOI: 10.1021/la800743a

Salleh, M. A. M., Mahmoud, D. K., Karim, W. A. W. A., and Idris, A. (2011). "Cationic and anionic dye adsorption by agricultural solid wastes: A comprehensive review," Desalination 280, 1-13. DOI: 10.1016/j.desal.2011.07.019

Schweich, D., and Sardin, M. (1981). "Adsorption, partition, ion-exchange and chemical-reaction in batch reactors or in columns - A review," J. Hydrology 50, 1-33. DOI: 10.1016/0022-1694(81)90059-7

Sen Gupta, S., and Bhattacharyya, K. G. (2011). "Kinetics of adsorption of metal ions on inorganic materials: A review," Advan. Colloid Interface Sci. 162, 39-58. DOI: 10.1016/j.cis.2010.12.004

Senthilkumaar, S., Kalaamani, P., and Subburaam, C. V. (2006). "Liquid phase adsorption of crystal violet onto activated carbons derived from male flowers of coconut tree," J. Hazard. Mater. 136(3), 800-808. DOI: 10.1016/j.jhazmat.2006.01.045

Shen, L., and Chen, Z. X. (2007). "Critical review of the impact of tortuosity on diffusion,” Chem. Eng. Sci. 62(14), 3748-3755. DOI: 10.1016/j.ces.2007.03.041

Sobkowski, J., and Czerwiński, A. (1974). "Kinetics of carbon dioxide adsorption on a platinum electrode," J. Electroanal. Chem. 55(3), 391-397. DOI: 10.1016/S00220728(74)80433-X

Soustelle, M. (2011). An Introduction to Chemical Kinetics, Wiley, Hoboken, NJ, USA, pp. 448. DOI: 10.1002/9781118604243

Stone, J. E., and Scallan, A. M. (1968). "A structural model for the cell wall of waterswollen wood pulp fibres based on their accessibility to macromolecules," Cellulose Chem. Technol. 2, 343-358.

Suhas, Gupta, V. K., Carrott, P. J. M., Singh, R., Chaudhary, M., and Kushwaha, S. (2016). "Cellulose: A review as natural, modified and activated carbon adsorbent," BioResour. Technol. 216, 1066-1076. DOI: 10.1016/j.biortech.2016.05.106

Sun, Q. Y., and Yang, L. Z. (2003). "The adsorption of basic dyes from aqueous solution on modified peat-resin particle," Water Res. 37(7), 1535-1544. DOI: 10.1016/S0043-1354(02)00520-1

Suteu, D., and Bilba, D. (2005). "Equilibrium and kinetic study of reactive dye Brilliant Red HE-3B adsorption by activated charcoal," Acta Chimica Slovenica 52(1), 73-79.

Suteu, D., Malutan, T., and Bilba, D. (2010). "Removal of reactive dye Brilliant Red HE-3B from aqueous solutions by industrial lignin: Equilibrium and kinetics modeling," Desalination 225(1-3), 84-90. DOI: 10.1016/j.desal.2010.01.010

Suurnäkki, A., Li, T. Q., Buchert, J., Tenkanen, M., Viikari, L., Vuorinen, T., and Ödberg, L. (1997). "Effects of enzymatic removal of xylan and glucomannan on the pore size distribution of kraft fibres," Holzforschung 51(1), 27-33. DOI: 10.1515/hfsg.1997.51.1.27

Tan, I. A. W., Ahmad, A. L., and Hameed, B. H. (2008). "Adsorption of basic dye on high-surface-area activated carbon prepared from coconut husk: Equilibrium, kinetic and thermodynamic studies," J. Hazard. Mater. 154, 337-346. DOI: 10.1016/j.jhazmat.2007.10.031

Tan, K. L., and Hameed, B. H. (2017). "Insight into the adsorption kinetics models for the removal of contaminants from aqueous solutions," J. Taiwan Inst. Chem. Eng. 74, 25-48. DOI: 10.1016/j.jtice.2017.01.024 
Tanzifi, M., Yaraki, M. T., Kiadehi, A. D., Hosseini, S. H., Olazar, M., Bharti, A. K., Agarwal, S., Gupta, V. K., and Kazemi, A. (2018). "Adsorption of Amido Black 10B from aqueous solution using polyaniline/ $\mathrm{SiO}_{2}$ nanocomposite: Experimental investigation and artificial neural network modeling," J. Colloid Interface Sci. 510, 2246-261. DOI: 10.1016/j.jcis.2017.09.055

Teraoka, I., Landley, K. H., and Karasz, F. E. (1992). "Reptation dynamics of semirigid polymers in porous media," Macromol. 25(23), 6106-6112. DOI: 10.1021/ma00049a005

Thirumalisamy, S., and Subbian, M. (2010). "Removal of methylene blue from aqueous solution by activated carbon prepared from the peel of Cucumis sativa fruit by adsorption," BioResources 5(1), 419-437.

Tijssen, R., Schoenmakers, P. J., Bohmer, M. R., Koopal, L. K., and Billiet, H. A. H. (1993). "Lattice models for the description of partitioning adsorption and retention in reversed-phase liquid-chromatography, including surface and shape effects," $J$. Chromatography A 656, 135-196. DOI: 10.1016/0021-9673(93)80801-E

Torre, M., Rodriguez, A. R., and Sauracalixto, F. (1992). "Study of the interactions of calcium-ions with lignin, cellulose, and pectin," J. Agric. Food Chem. 40(10), 1762 1766. DOI: 10.1021/jf00022a007

Tseng, R.-L., Wu, K. T., Wu, F. C., and Juang, R. S. (2010). "Kinetic studies on the adsorption of phenol, 4-chlorophenol, and 2,4-dichlorophenol from water using activated carbons," J. Environ. Manag. 91(11), 2208-2214. DOI: 10.1016/j.jenvman.2010.05.018

Ujhelyiova, A., Bolhova, E., Oravkinova, J., Tino, R., and Marcincin, A. (2007). "Kinetics of dyeing process of blend polypropylene/polyester fibres with disperse dye," Dyes Pigments 72(2), 212-216. DOI: 10.1016/j.dyepig.2005.08.026

Vadivelan, V., and Kumar, K. V. (2005). "Equilibrium, kinetics, mechanism, and process design for the sorption of methylene blue onto rice husk," J. Colloid Interface Sci. 286(1), 90-100. DOI: 10.1016/j.jcis.2005.01.007

Vallance, C. (2017). Introduction to Chemical Kinetics, IOP Publ. Ltd. DOI: 10.1088/978-1-6817-4664-7

Vanbrakel, J., and Heertjes, P. M. (1974). "Analysis of diffusion in macroporous media in terms of a porosity, a tortuosity and a constrictivity factor," Int. J. Heat Mass Trans. 17(9), 1093-1103. DOI: 10.1016/0017-9310(74)90190-2

Varadarajan, G., and Venkatachalam, P. (2016). "Sustainable textile dyeing processes," Environ. Chem. Lett. 14(1), 113-122. DOI: 10.1007/s10311-015-0533-3

Vázquez, C., Mosquera, O., Freire, M. S., Antorrena, G., González-Álvarez, J. (2012). "Alkaline pretreatment of waste chestnut shell from a food industry to enhance cadmium, copper, lead, and zinc ions removal," Chem. Eng. J. 184, 147-155. DOI: 10.1016/j.cej.2012.01.019

Vijayaraghavan, K., and Yun, Y. S. (2007). "Chemical modification and immobilization of Corynebacterium glutamicum for biosorption of Reactive Black 5 from aqueous solution," Indust. Eng. Chem. Res. 46(2), 608-617. DOI: 10.1021/ie061158g

Wachinski, A. M. (2017). Environmental Ion Exchange: Principles and Design, CRC Press, Taylor and Francis, Boca Raton, FL. DOI: $10.1201 / 9781315368542$

Wågberg, L., Ödberg, L., Lindström, T., and Aksberg, R. (1988). "Kinetics of adsorption and ion-exchange reactions during adsorption of cationic poly-electrolytes onto cellulosic fibers," J. Colloid Interface Sci. 123(1), 287-295. DOI: 10.1016/00219797(88)90245-7 
Wang, B., and Shi, B. L. (2010). "Comparison of surface tension components and Hansen solubility parameters theories. Part I: Explanation of protein adsorption on polymers," J. Macromol. Sci. Part B - Phys. 49(2), 383-391. DOI: 10.1080/00222340903356253

Wang, C., and Luo, M. B. (2007). "Effect of interchain interactions on the translocation of polymer chains through small holes," J. Appl. Polymer Sci. 103(2), 1200-1205. DOI: 10.1002/app.25381

Wang, Z. M., and Giammar, D. E. (2013). "Mass action expressions for bidentate adsorption in surface complexation modeling: Theory and practice," Environ. Sci. Technol. 47(9), 3982-3996. DOI: 10.1021/es305180e

Waranusantigul, P., Pokethitiyook, P., Kruatrachue, M., and Upatham, E. S. (2003). "Kinetics of basic dye (methylene blue) biosorption by giant duckweed (Spirodela polyrrhiza)," Environmental Pollution 125, 385-392. DOI: 10.1016/S02697491(03)00107-6

Watanabe, U., Norimoto, M., and Morooka, T. (2000). "Cell wall thickness and tangential Young's modulus in coniferous early wood," J. Wood Sci. 46(2), 109-114. DOI: $10.1007 / \mathrm{BF} 00777356$

Weber, Jr., W. J., and Morris, J. C. (1963). "Kinetics of adsorption on carbon from solution," J. Sanit. Eng. Div. Am. Soc. Civ. Eng. 89, 31-60.

Wolterink, J. K., Barkema, G. T., and Panja, D. (2006). "Passage times for unbiased polymer translocation through a narrow pore," Phys. Rev. Let. 96(20), article 208301. DOI: 10.1103/PhysRevLett.96.208301

Wu, F. C., Tseng, R. L., Huang, S. C., and Juang, R. S. (2009a). "Characteristics of pseudo-second-order kinetic model for liquid-phase adsorption: A mini-review," Chem. Eng. J. 151, 1-9. DOI: 10.1016/j.cej.2009.02.024

Wu, N., Hubbe, M. A., Rojas, O. J., and Park, S. (2009b). "Permeation of polyelectrolytes and other solutes into the pore spaces of water-swollen cellulose: A review," BioResources 4(3), 1222-1262.

Xing, Y., and Deng, D. H. (2009). "Enhanced adsorption of malachite green by EDTAD-modified sugarcane bagasse," Separ. Sci. Technol. 44(9), 2117-2131. DOI: $10.1080 / 01496390902775588$

Yagub, M. T., Sen, T. K., Afroze, S., and Ang, H. M. (2014). "Dye and its removal from aqueous solution by adsorption: A review," Adv. Colloid Interface Sci. 209, 172-184. DOI: 10.1016/j.cis.2014.04.002

Yahya, M. A., Al-Qodah, Z., and Ngah, C. W. Z. (2015). "Agricultural bio-waste materials as potential sustainable precursors used for activated carbon production: A review," Renew. Sustain. Energy Rev. 46, 218-235. DOI: 10.1016/j.rser.2015.02.051

Zhang, H. Y., Chen, L. J., Lu, M. S., Li, J. B., and Han, L. J. (2016). “A novel filmpore-surface diffusion model to explain the enhanced enzyme adsorption of corn stover pretreated by ultrafine grinding," Biotech. Biofuels 9, article no. 181. DOI: 10.1186/s13068-016-0602-2 


\section{APPENDIX}

Table A. Listing of Equations to Fit Adsorption Kinetic Data

\begin{tabular}{|l|c|l|l|}
\hline Equation name & Equation & $\begin{array}{l}\text { Eq. } \\
\#\end{array}$ & $\begin{array}{l}\text { Selected } \\
\text { references }\end{array}$ \\
\hline $\begin{array}{l}\text { Pseudo-first-order, } \\
\text { differential form }\end{array}$ & $\frac{\mathrm{d} q}{\mathrm{~d} t}=k_{1}\left(q_{e}-q\right)$ & 4 & Lagergren 1898 \\
\hline $\begin{array}{l}\text { Pseudo-first-order, } \\
\text { integrated form }\end{array}$ & $\ln \left(q_{e}-q_{t}\right)=\ln q_{e}-k_{1} t$ & 1 & $\begin{array}{l}\text { Blanchard et al. } \\
1984 ; \text { Ho 2006b }\end{array}$ \\
\hline $\begin{array}{l}\text { Pseudo-second-order, } \\
\text { differential form }\end{array}$ & $\frac{\mathrm{d} q}{\mathrm{~d} t}=k_{2}\left(q_{e}-q\right)^{2}$ & $3 \mathrm{~A}$ & $\begin{array}{l}\text { Sobkowski \& } \\
\text { Czersiński 1974; } \\
\text { Ho 2006b }\end{array}$ \\
\hline $\begin{array}{l}\text { Pseudo-second-order, } \\
\text { integrated form } \\
\text { (“Type 1") }\end{array}$ & $\frac{\theta}{1-\theta}=k_{2} t$ & $3 \mathrm{~B}$ & $\begin{array}{l}\text { Ritchie 1977; Ho } \\
2006 \mathrm{~b}\end{array}$ \\
\hline $\begin{array}{l}\text { Pseudo-second-order, } \\
\text { integrated form } \\
\text { (“Type 2") }\end{array}$ & $\frac{q_{\infty}}{q_{\infty}-q}=\alpha t+1$ & 3 & $\begin{array}{l}\text { Blanchard et al. } \\
1984 ; \text { Ho 2006b }\end{array}$ \\
\hline $\begin{array}{l}\text { Pseudo-second-order, } \\
\text { integrated form } \\
\text { (“Type 3”) }\end{array}$ & $\frac{1}{q_{o}-q}-\alpha=k_{2} t$ & $3 \mathrm{D}$ & $\begin{array}{l}\text { Ho 2006 (from } \\
1995 \text { thesis) }\end{array}$ \\
\hline $\begin{array}{l}\text { Pseudo-second-order, } \\
\text { integrated form } \\
\text { (“Type 4”) }\end{array}$ & $\frac{t}{q_{t}}=\frac{1}{k_{2} q_{e}^{2}}+\frac{1}{q_{e} t}$ & 12 & $\begin{array}{l}\text { Canzano et al. } \\
\text { (2012) }\end{array}$ \\
\hline $\begin{array}{l}\text { Pseudo-second-order, } \\
\text { integrated form }\end{array}$ & $q_{t}=\frac{k_{2} q_{e}^{2} t}{1+k_{2} q_{e} t}$ or $q_{t}=\frac{t}{\frac{1}{k_{2} q_{e}^{2}}+\frac{t}{q_{e}}}$ & & \\
\hline
\end{tabular}

Definitions:

$\alpha=\mathrm{a}$ coefficient

$k_{1}=$ rate constant for a first-order reaction

$k_{2}=$ rate constant for a second-order reaction

$t=$ time

$q=$ adsorbed amount

$q_{e}=$ adsorbed amount at equilibrium

$q_{t}=$ adsorbed amount at time $=t$

$q_{\infty}=$ adsorbed amount at infinite time

$\theta=$ fraction of available sites that are occupied 


\section{ERRATUMS}

August 7, 2019:

Equation 7 was changed from " $\mathrm{d}(\mathrm{AB}) / \mathrm{d} t=k[\mathrm{~A}][\mathrm{B}]$ " to " $\mathrm{d}[\mathrm{AB}] / \mathrm{d} t=k[\mathrm{~A}][\mathrm{B}]$ "

Equation 8 was changed from " $\mathrm{d}(\mathrm{AB}) / \mathrm{d} t=k$ ' $[\mathrm{B}]$ ” to " $\mathrm{d}[\mathrm{AB}] / \mathrm{d} t=k$ ' $[\mathrm{B}]$ ”

Equation 10 was changed from " $\mathrm{d}\left(\mathrm{A}_{2}\right) / \mathrm{d} t=k[\mathrm{~A}]^{2 "}$ to " $\mathrm{d}\left[\mathrm{A}_{2}\right] / \mathrm{d} t=k[\mathrm{~A}]^{2 "}$

Equation 16 was changed from " $\frac{\partial C}{\partial t}=D \frac{\partial^{2} C_{p}}{\partial x^{2}}-\frac{\partial S}{\partial t}$ " to " $\frac{\partial C_{p}}{\partial t}=D \frac{\partial^{2} C_{p}}{\partial x^{2}}-\frac{\partial S}{\partial t}$,

Equation 17 was changed from " $\frac{\partial C}{\partial t}=\frac{D}{R+1} \frac{\partial^{2} C_{p}}{\partial x^{2}}$ " to " $\frac{\partial C_{p}}{\partial t}=\frac{D}{R+1} \frac{\partial^{2} C_{p}}{\partial x^{2}}$,

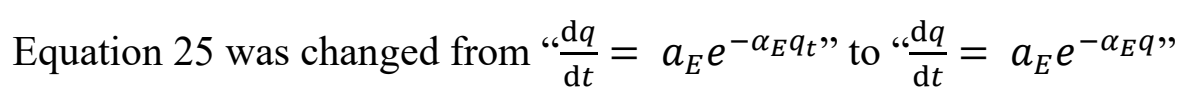

